This post presents two papers. The first is a "Guide to Fair and Square Redistricting." This Guide is written for citizens, advocates and commissioners, as well as legislators and judges. The Guide highlights the essence of a new procedure for drawing fair legislative maps.

The second paper, "Fair and Square Redistricting" details, justifies and applies this new approach to constructing fair legislative district maps. The procedure is deliberately transparent, systematic and research-based. It can be, and was, implemented by hand. The approach can be used to construct fair maps of either Congressional or State Legislative districts. 


\section{GUIDE TO FAIR AND SQUARE REDISTRICTING}

James N. Fox

A new procedure has been developed to construct fair legislative district maps. This new approach is justified, explained in detail, and applied in the following paper, "Fair and Square Redistricting." This guide presents a quick overview of the Fair and Square approach.

\section{What does Fair and Square Redistricting do?}

The Fair and Square procedure draws Congressional or State Legislative district maps that are free from gerrymandering. A gerrymandered map constructs districts that deliberately group voters together in a way that gives one party or the other an unfair advantage. The result is often oddly shaped districts. ${ }^{1}$ An approach such as the Fair and Square procedure solves this problem. The diagram below shows, for example, a gerrymandered Congressional district map that was adjudicated before the Supreme Court (on the left) ${ }^{2}$ alongside a rendering of the Congressional district map generated by the Fair and Square approach for that state (on the right).
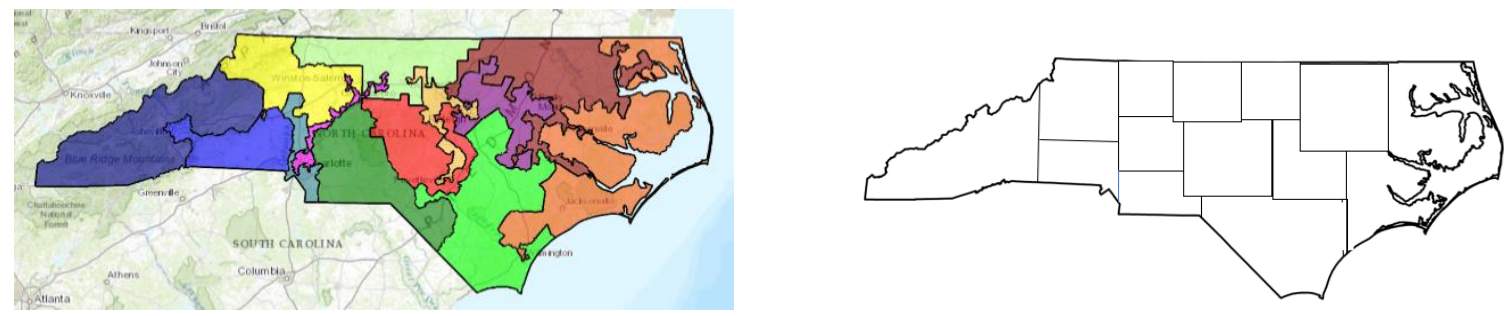

${ }^{1}$ Certain states explicitly prohibit districts that are "oddly shaped," "irregularly shaped," or have a "bizarre shape." National Conference of State Legislatures, "Redistricting Criteria." Washington, D.C: NCSL, 2019. ncsl.org/research/redistricting/redistricting-criteria.aspx

${ }^{2}$ A new map was drawn for one-time use in the 2020 election. The paper, "Fair and Square Redistricting," studies 12 states where district maps have recently been challenged in court. 


\section{How does the Fair and Square procedure work?}

The Fair and Square approach is a two-step procedure. In Step 1 mapmakers create rows of (nested) square districts. This provides the foundation of the procedure. In Step 2, the mapmakers build upon this foundation. They maintain the square shape of districts as much as possible, and adjust district lines as needed to assure that the set of districts is fair.

\section{What does "fair" mean?}

Suppose, for example, that in past elections, 60 percent of all voters in a state voted for Party A and $40 \%$ voted for Party B. A fair procedure generates a map where $60 \%$ of the districts contain a majority of voters who chose Party $A$ in past elections, and $40 \%$ of the districts contain a majority of voters who chose Party B.

\section{Why are districts square?}

Past research has shown that citizens and redistricting experts alike see square districts as being most "compact." ${ }^{3}$ Compact districts are important because then neighbors vote with neighbors and representatives can focus on issues relevant to a local community. ${ }^{4}$ Also, housing patterns tend to be related to communities of interest, so compact districts allow elected officials to represent constituents in those communities.

\section{Why aren't all districts the same size?}

Districts must be (nearly) the same size in terms of population so each elected official represents about the same number of constituents. However, population density varies across a state. Therefore, to contain the same population, districts in rural areas will be geographically large and districts in densely populated areas will be geographically small.

\footnotetext{
${ }^{3}$ Aaron Kaufman, Gary King and Mayya Komisarchik, "How to Measure Legislative District Compactness If You Only Know It When You See It,” American Journal of Political Science, Forthcoming. Copy at https://gking.harvard.edu/files/gking/files/compact.pdf

${ }^{4}$ The National Conference of State Legislatures reports that 40 states require that districts be compact. National Conference of State Legislatures, "Redistricting Criteria.” Washington, D.C.: NCSL, 2019.
} 
Why can't districts simply be placed side-by-side; Why must they be “nested?'

Districts vary in geographic size. As a result, if districts were placed side by side, residents in certain areas of the state would not be included in a district. The diagram below shows four square districts (red, green, blue, purple) placed sideby-side. The residents in the rectangular area are not included in any district.

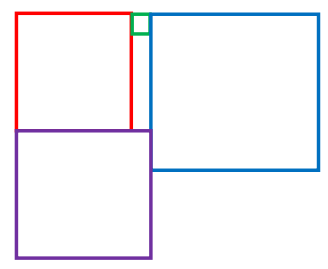

The Fair and Square approach presents a procedure for tucking some of the square districts under others to assure that all voters are included in a district.

\section{Why aren't the sides of districts straight?}

Districts are made up of precincts grouped together. Precincts often do not have smooth sides, so the sides of districts are not perfectly smooth.

Does the Fair and Square procedure use a computer program to draw the maps?

No. The Fair and Square approach is completely transparent and can be, and was, implemented by hand. A computer assisted app, called Dave's Redistricting, was used to keep track of the voters in each district as the districts were drawn.

\section{What is the goal of Fair and Square Redistricting?}

Fair and Square Redistricting is offered as a tool to contest gerrymandering. The intent is to help those interested in redistricting become aware of straightforward, fair approaches for drawing legislative district maps. Advocates can then use that knowledge to demand that such approaches be used to draw the maps in their states. In short, the goal is to help citizens, advocates and commissioners, as well as legislators and judges, use approaches such as the Fair and Square procedure to finally lay the gerrymandering dragon to rest. 


\title{
FAIR AND SQUARE REDISTRICTING
}

\author{
James N. Fox ${ }^{5}$
}

\begin{abstract}
This article presents a new procedure for constructing fair legislative district maps. This straightforward, transparent, research-based procedure is intended to be helpful to those interested in promoting fair legislative district maps. The work draws upon a recent awardwinning study of preferences of redistricting experts and lay citizens, alike. The approach draws upon that study to construct foundational legislative district maps. The mapping procedure then builds on that foundation, employing the well-established concept of partisan symmetry to construct maps that are fair to both major political parties. The article opens by discussing this new view of compact districts and describes the procedure for constructing the maps.

Foundational maps are drawn for 12 states that have recently been under court scrutiny. Partisan symmetry is then applied to these maps to construct legislative district maps that are fair and square.
\end{abstract}

\section{INTRODUCTION}

Mapmakers will soon redraw legislative district maps in response to the 2020 Census. They face a task more daunting than ever before. Myriad computer algorithms are available, such as the shortest splitline, Voroni Diagrams, the Kmeans algorithm (Altman and McDonald 2010, pp. 86,88) and Brian Olson's minimizing the distance from the center approach (Olson, n.d). An expert generated 24,518 compliant congressional district maps for North Carolina in the recent Rubio litigation (dissent, p. 20). Which road will mapmakers follow; which path will they take?

This article offers a path for mapmakers to consider. The article presents a nonpartisan procedure for constructing legislative district maps. The maps contain compact districts and are fair to both major political parties. A straightforward, transparent procedure such as this is likely to be appreciated by advocates, citizens, and jurists, alike.

\footnotetext{
${ }^{5}$ B.A. Stanford, M.A., PhD. ${ }^{\text {abd }}$ UCLA; ORCID iD: https://orcid.org/0000-0001-9493-8275?lang=en.
} 


\section{COMPACT DISTRICTS}

State Requirements. The National Conference of State Legislatures (NCSL) (2019) reports that 40 states require that legislative districts be "compact." But what does "compact" mean? Based on a comprehensive review of legislation and constitutional provisions in all 50 states, Levitt (2018) concludes, "Few states define precisely what 'compactness' means, but a district in which people generally live near each other is usually more compact than one in which they do not. Most observers look to measures of a district's geometric shape." NCSL points out, for example, in Arkansas, the Courts have held that "a district shaped like a circle or a square would be 'geographically compact;"' In Iowa, state provisions define "reasonable compact districts" as "those which are square, rectangular, or hexagonal in shape;" and the districts should not be "irregularly shaped." Nevada provisions call for districts that are "as regularly shaped as possible (e.g. rectangular or circular)." In Arkansas, the Courts say to avoid districts with a "bizarre shape;" and Idaho provisions say to "avoid drawing districts that are "oddly shaped" (National Conference of State Legislatures 2019).

Individuals' Perceptions. A recent award-winning study sheds additional light on this issue. Kaufman, King and Komisarchik (forthcoming) investigated individuals' perceptions about which district shapes appear to be most compact. These researchers employed sophisticated interview techniques to elicit the views of almost 200 respondents covering a broad range of both redistricting experts and lay citizens.

Our main test comes from 96 sitting justices, judges, and public officials, all with some responsibility for redistricting or deciding redistricting cases. We also elicited the views of 102 others ranging from less to more involved in and knowledgeable about redistricting, including Mechanical Turk workers ... undergraduates . . . political science PhD students, law students, law faculty, redistricting consultants and expert witnesses, and lawyers involved in legislative redistricting cases (p. 17 ). 
They found remarkable consistency among all respondents. "Our measure of compactness favors districts that are squarish, with minimal arms, pockets, islands, or jagged edges. (We use "squarish" rather than "circle-like" because many real districts are approximately square-shaped but almost none resemble circles.)" (p. 9) (See also Figure 2 and Table 2). They also found that respondents prefer shapes that are not tilted (p. 8).

Related State Practice. States can, and do, use squares to frame various subdivisions. Witness for example the precinct maps for Michigan and Wisconsin and the county map of Iowa.

Figure 1. Square Precincts in Michigan and Wisconsin and Square Counties in Iowa

Michigan

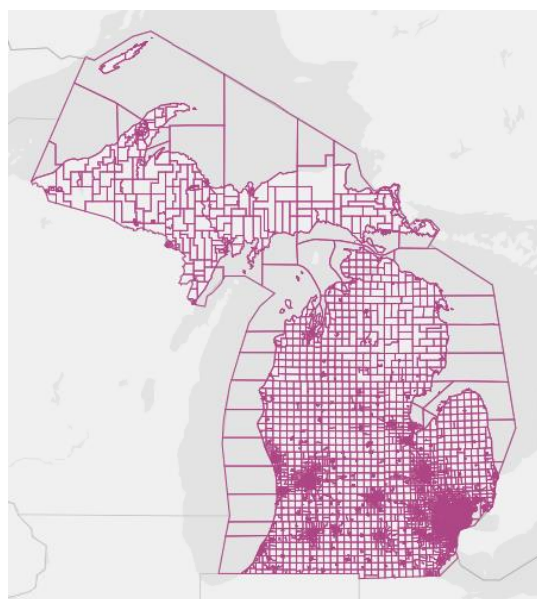

Wisconsin

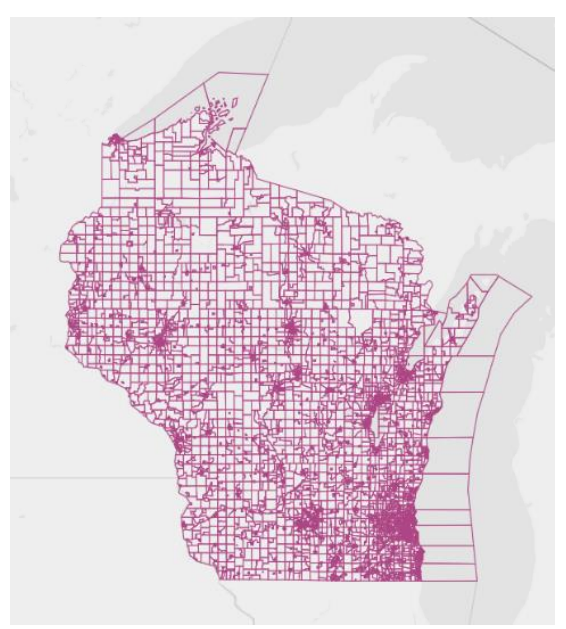

Iowa

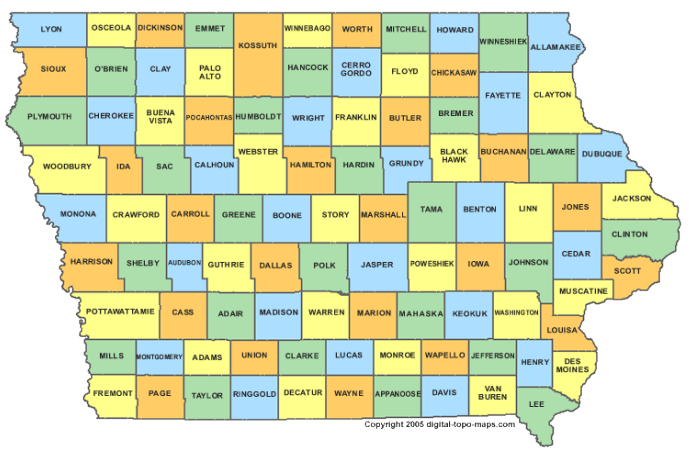




\section{A NONPARTISAN TRANSPARENT PROCEDURE FOR CONSTRUCTING LEGISLATIVE DISTRICT MAPS}

Nested Squares. This section of the article presents a straightforward, transparent procedure to construct nonpartisan legislative maps formed by upright (not tilted) square, compact districts. Square districts cannot simply be placed side-by-side to construct a legislative map. Federal and state requirements stipulate that legislative districts must contain (approximately) equal population (NCSL 2019). Each state has a predetermined number of congressional districts (or within state senators or delegates). The required population in each district is the state's total population divided by the number of predetermined districts. Districts in densely populated areas will be geographically smaller than districts in more sparsely populated areas. To assure that all areas of the state are covered, this procedure uses nested squares.

To construct a map of nested squares, start at the upper left of a state map and draw a square which expands to the right and down until the district contains the required population. Then move to the upper left corner of the unoccupied area and proceed from left to right (as we read in America). Produce a series of adjoining squares across the top of the map. Then move to the far left of the unclaimed area in the map and draw the second row of districts. Continue the process until the map is complete. Whenever a square meets an already claimed area, "tuck" the new square under the existing square and readjust the size of the square to meet the population requirement. The result is a map of compact nested squares. ${ }^{6}$ The procedure is straightforward and transparent. It can be done by hand.

Application. The Brennan Center has identified redistricting cases in 12 states ( $\mathrm{Li}$, Wolf and Lo 2019). Shown below, for each of these states, is the current congressional district map alongside a conceptual rendering of the map drawn by the nonpartisan nested squares approach.

\footnotetext{
${ }^{6} \mathrm{Appendix} A$ describes in detail the procedure for constructing a legislative district map with compact districts made up of nested squares.
} 
Figure 2. Congressional District Maps ${ }^{7}$

\section{Current}

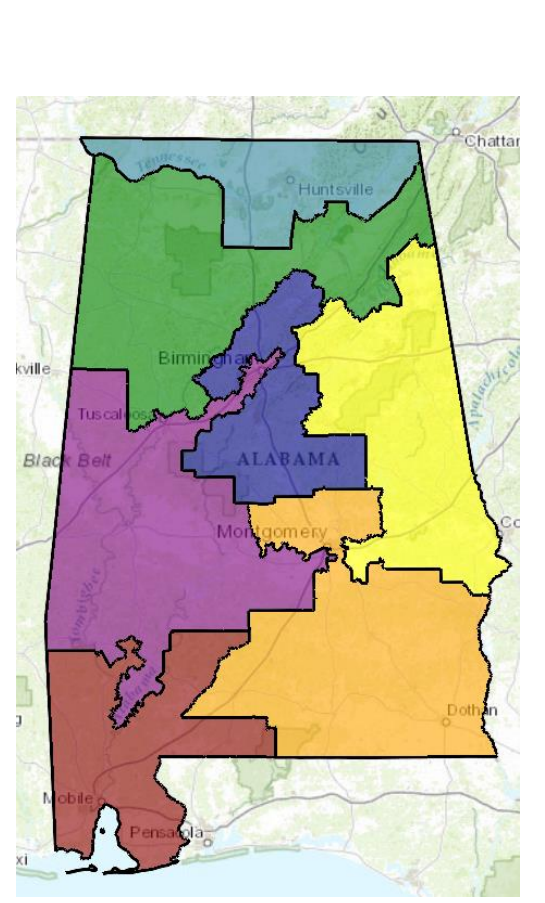

$\underline{\text { Nested Squares }}$

ALABAMA

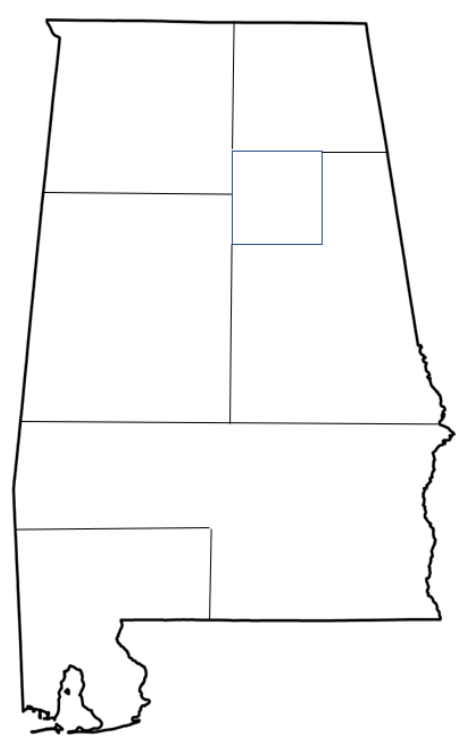

${ }^{7}$ Current maps are from Wikipedia except Ohio which is from Cleveland State University. State outlines for the nested square maps are from Gisgeography.com. 


\section{CONNECTICUT}
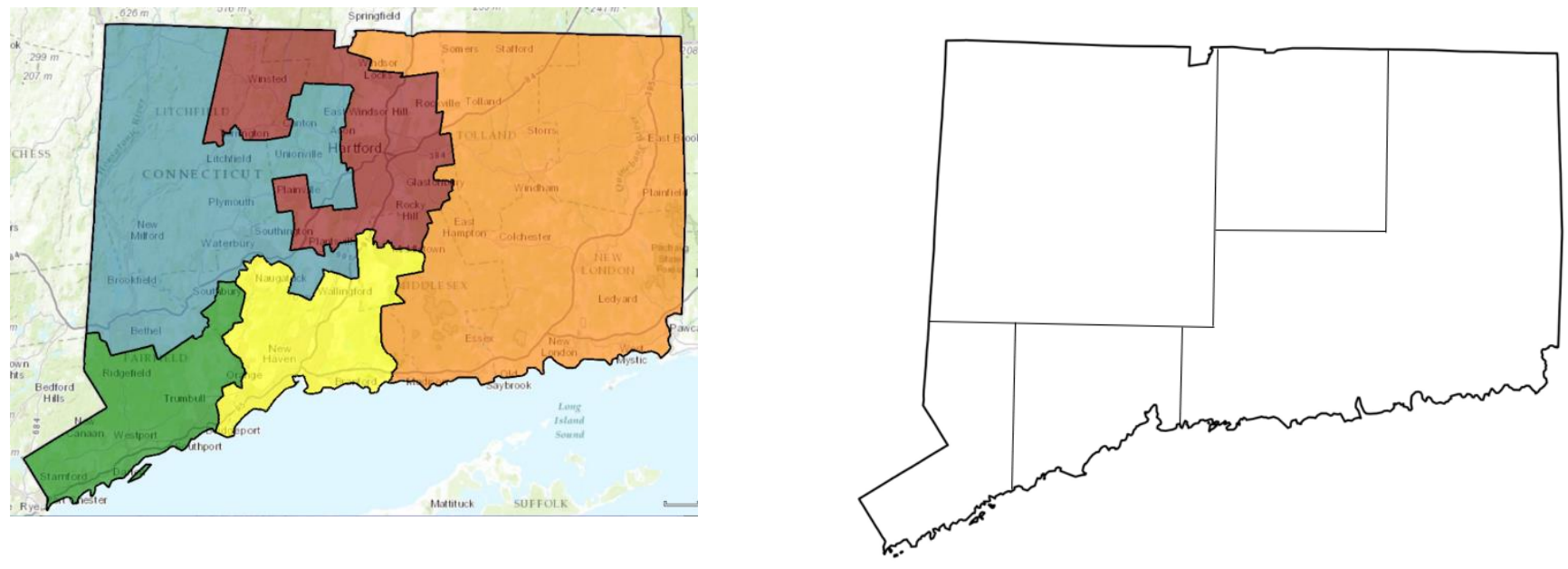

\section{GEORGIA}
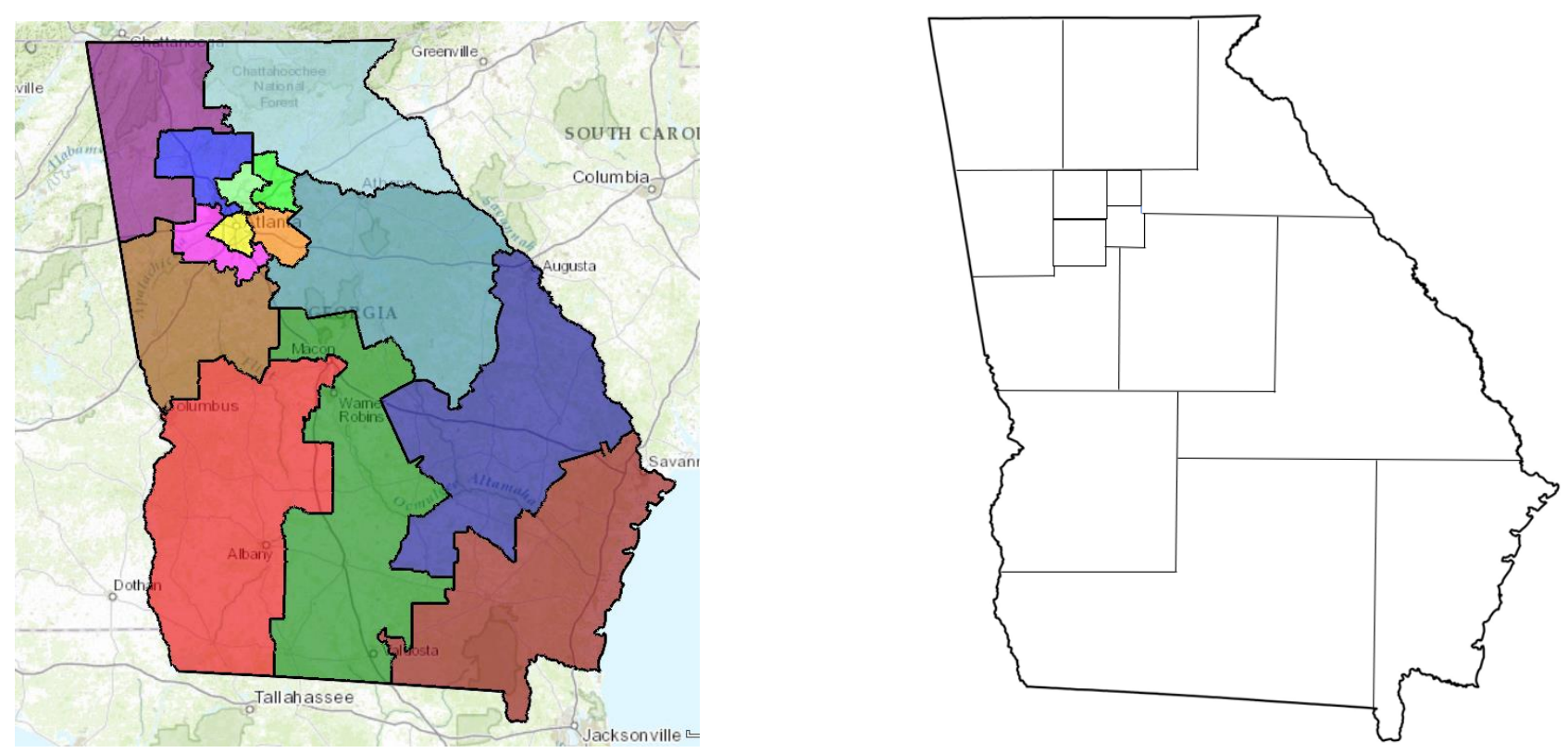


\section{LOUISIANA}
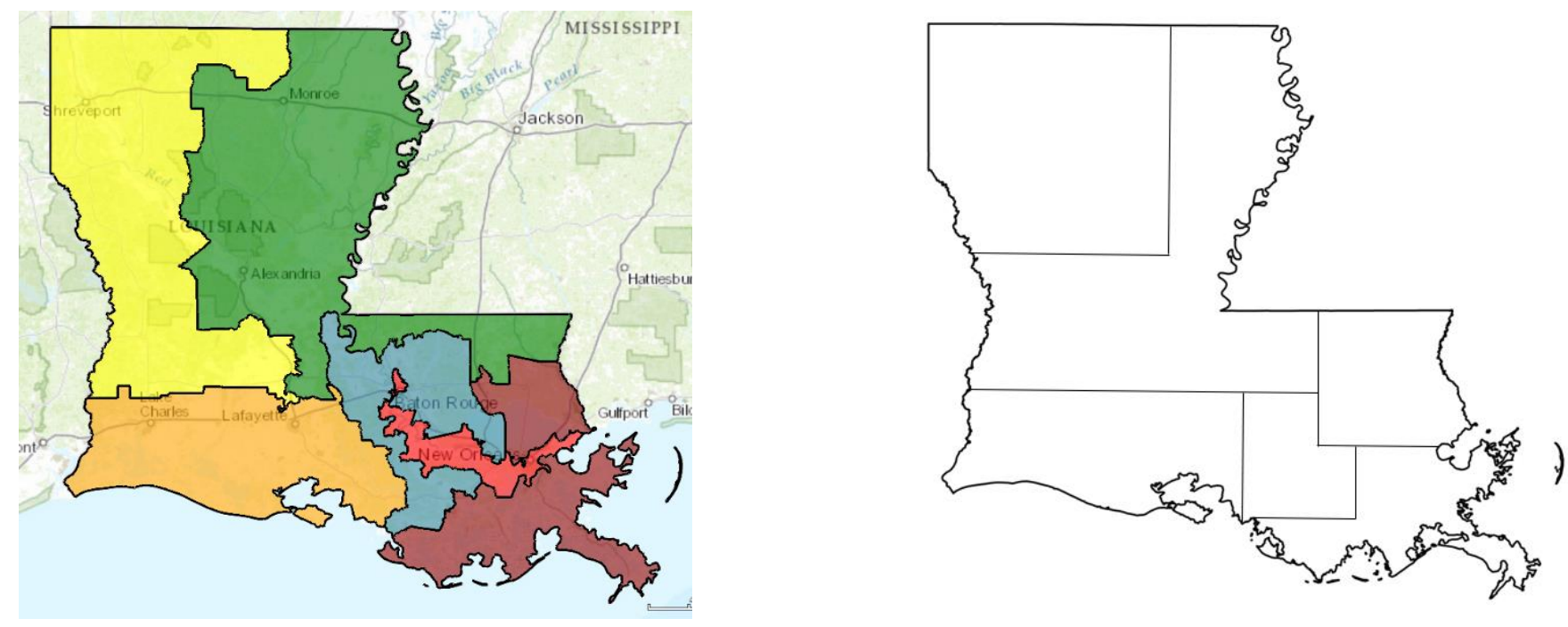

\section{MICHIGAN}
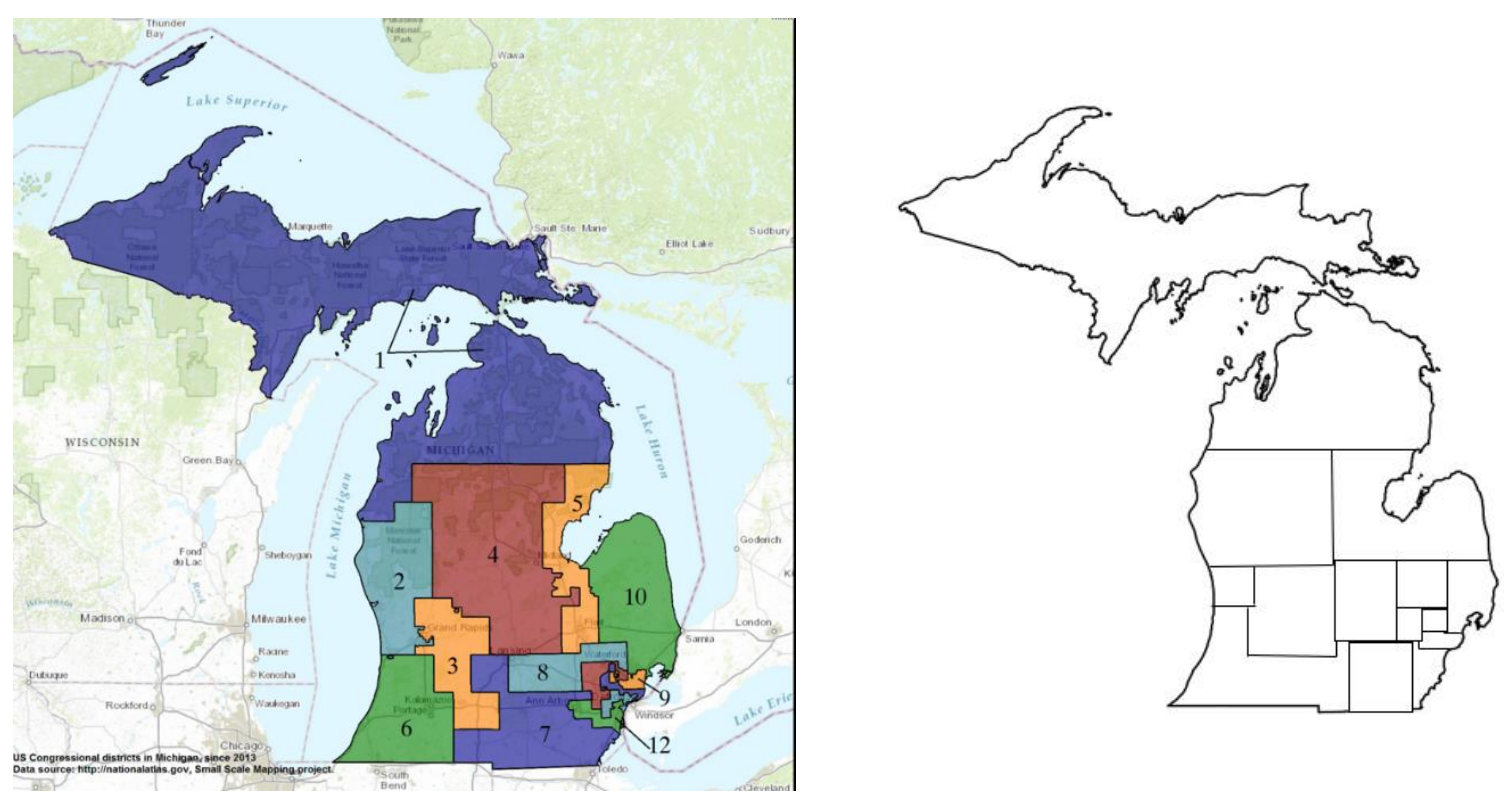


\section{MARYLAND}
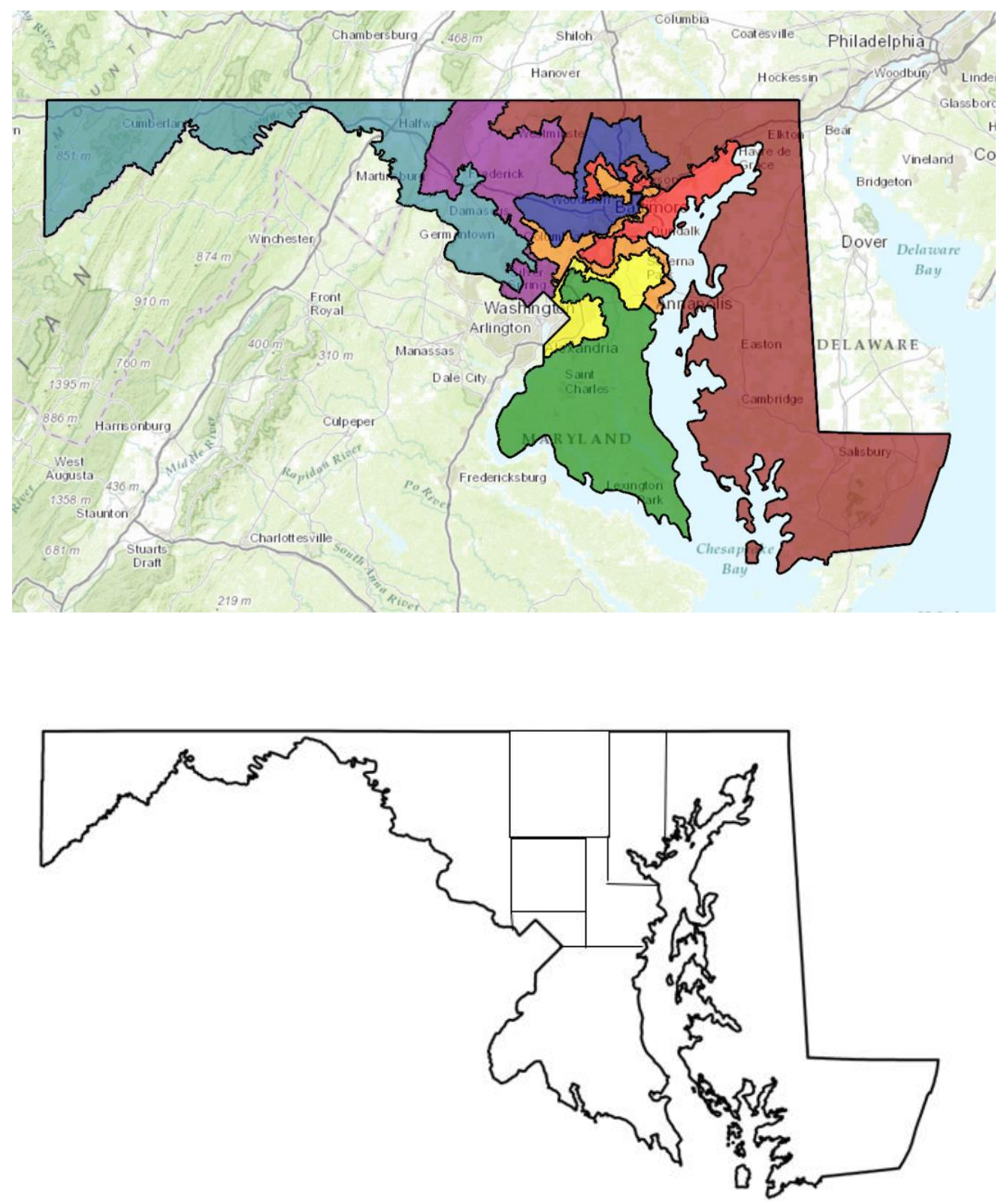


\section{MISSISSIPPI}
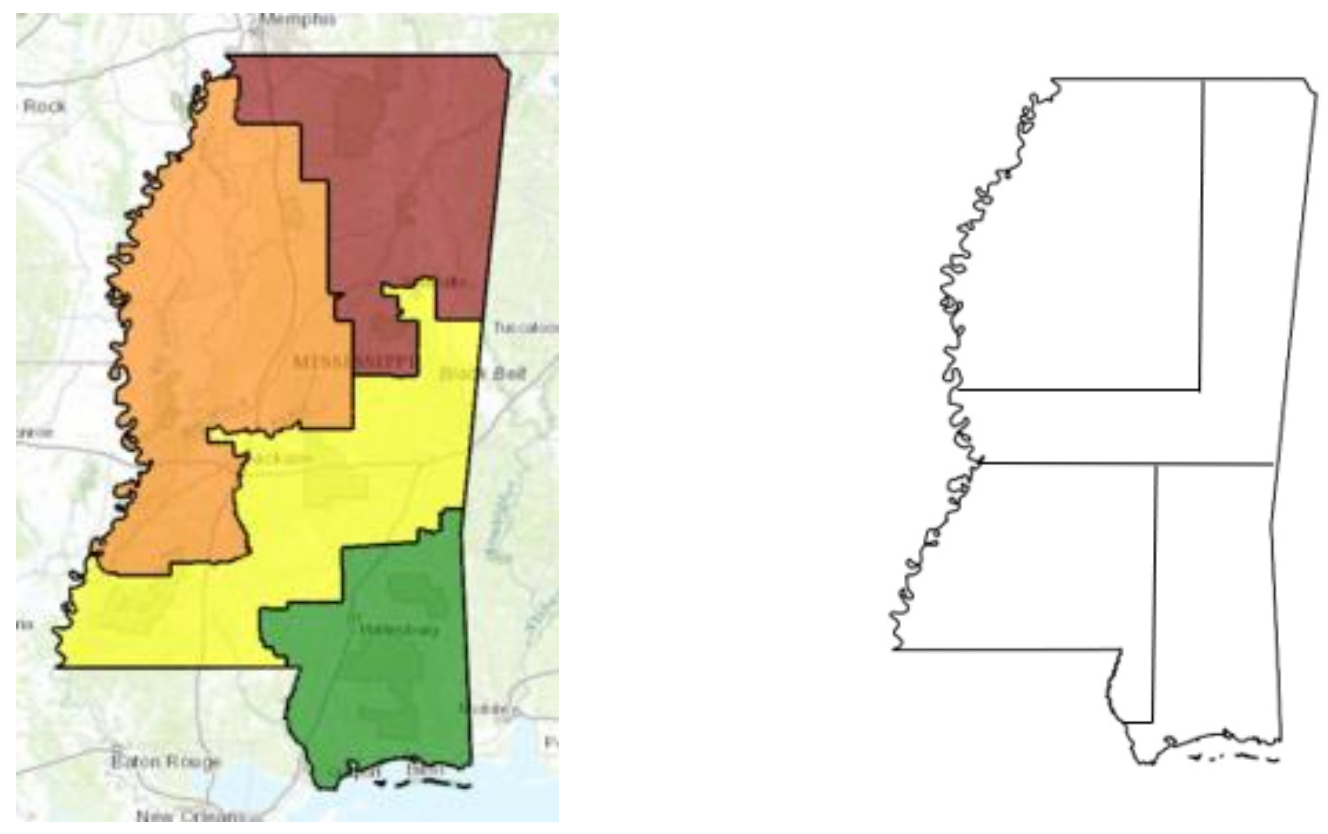

\section{OHIO}
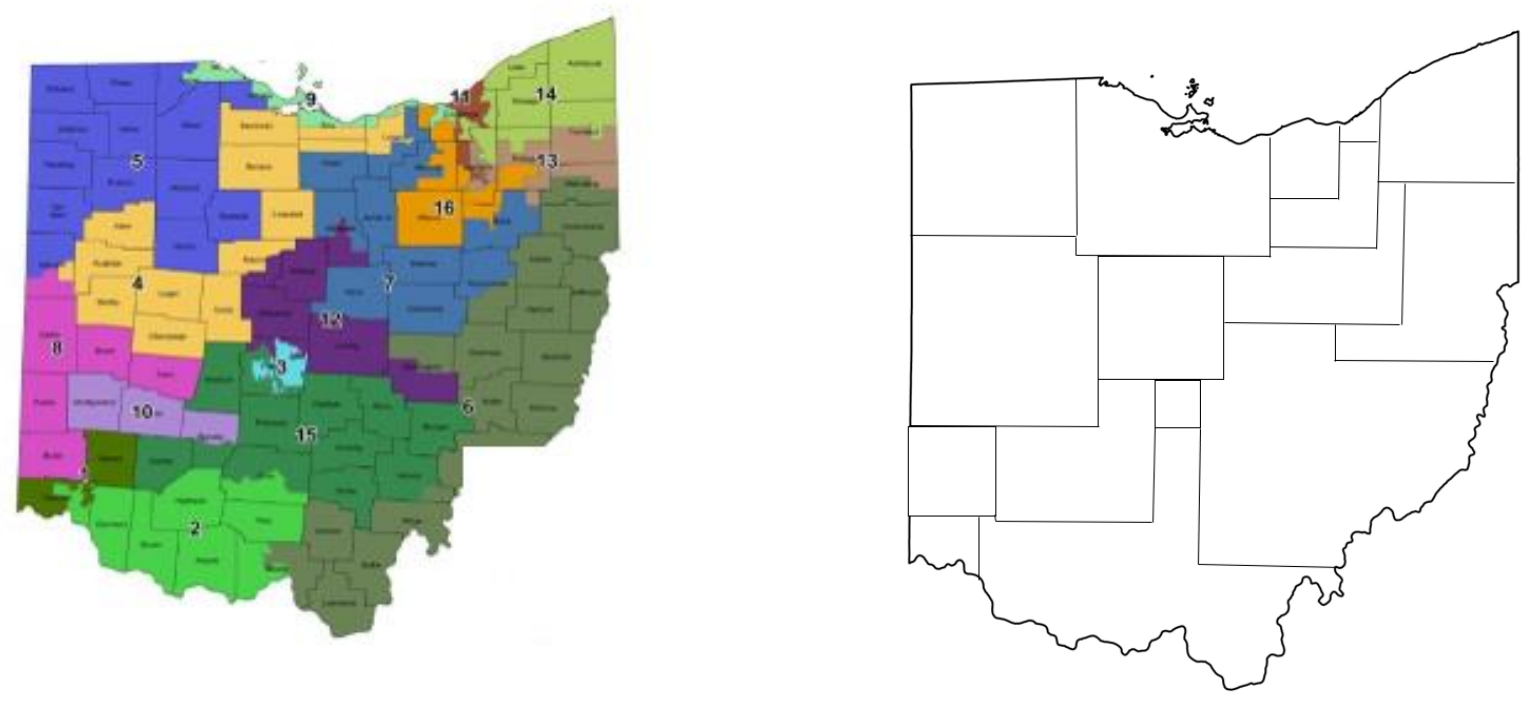


\section{NORTH CAROLINA ${ }^{8}$}
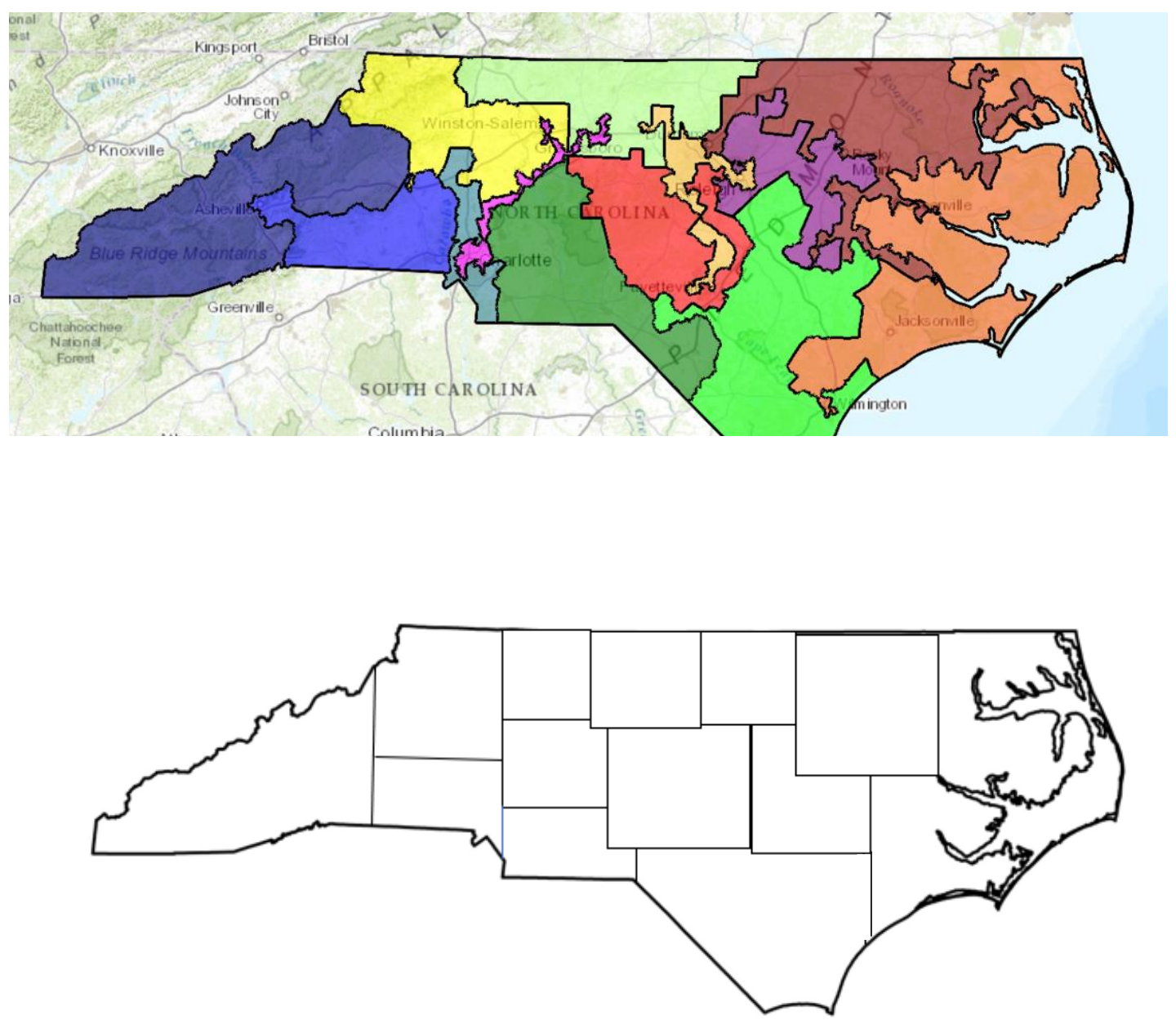

${ }^{8}$ This is the map that was adjudicated in Rucho. A new map has been drawn for one time use in the 2020 election (Melnik and Meko 2019). 


\section{TEXAS}
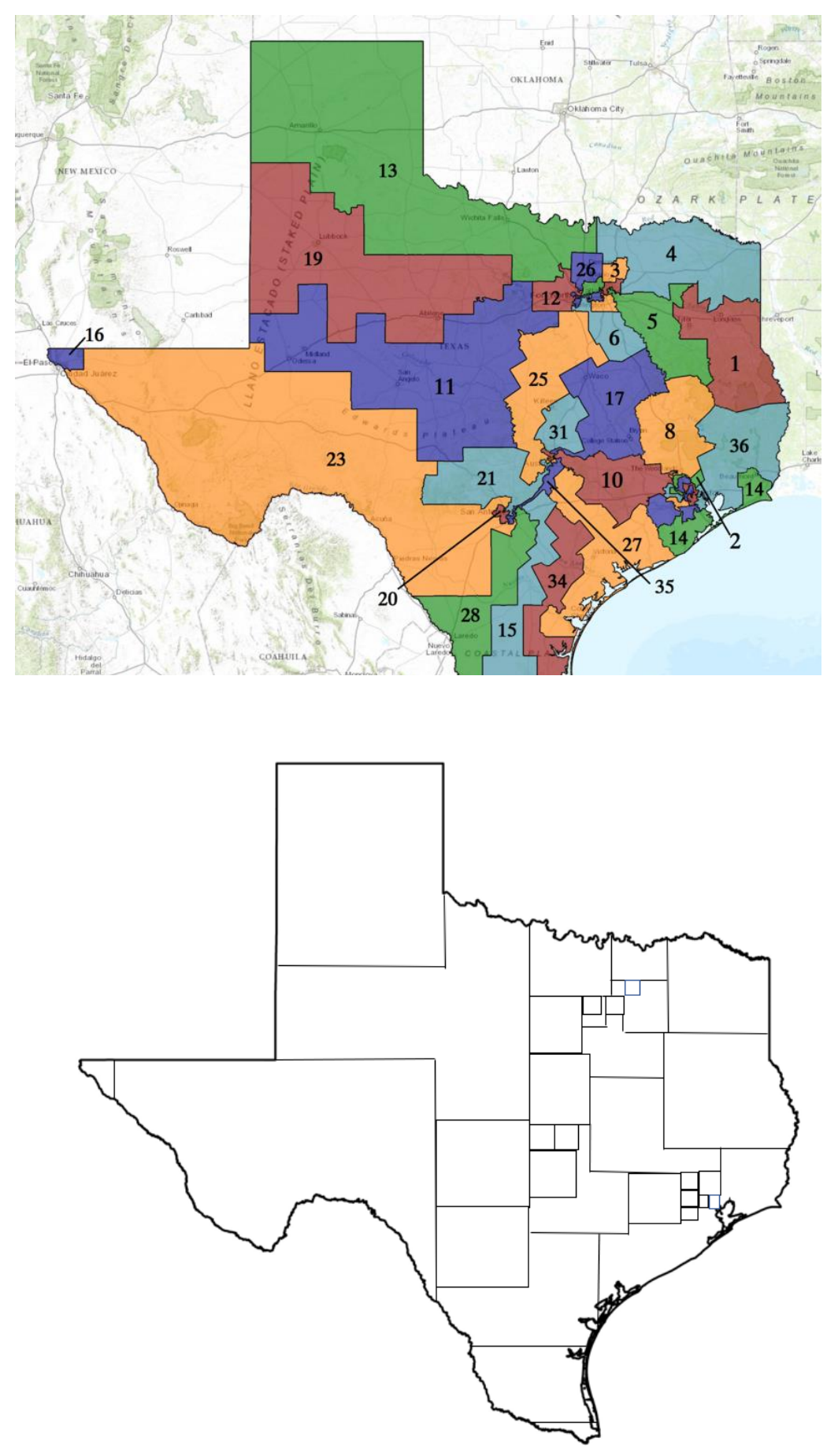


\section{VIRGINIA}
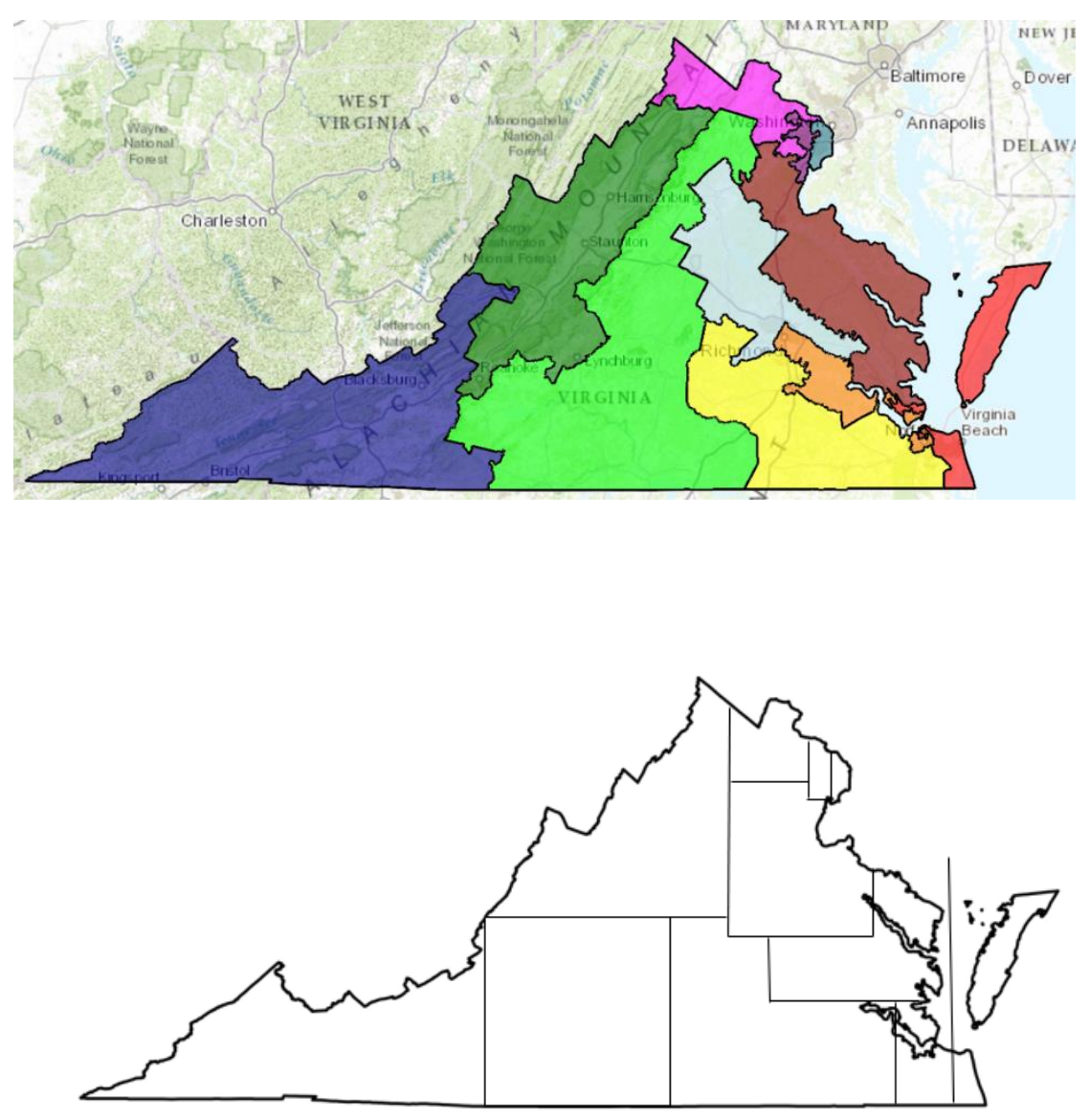


\section{WISCONSIN}
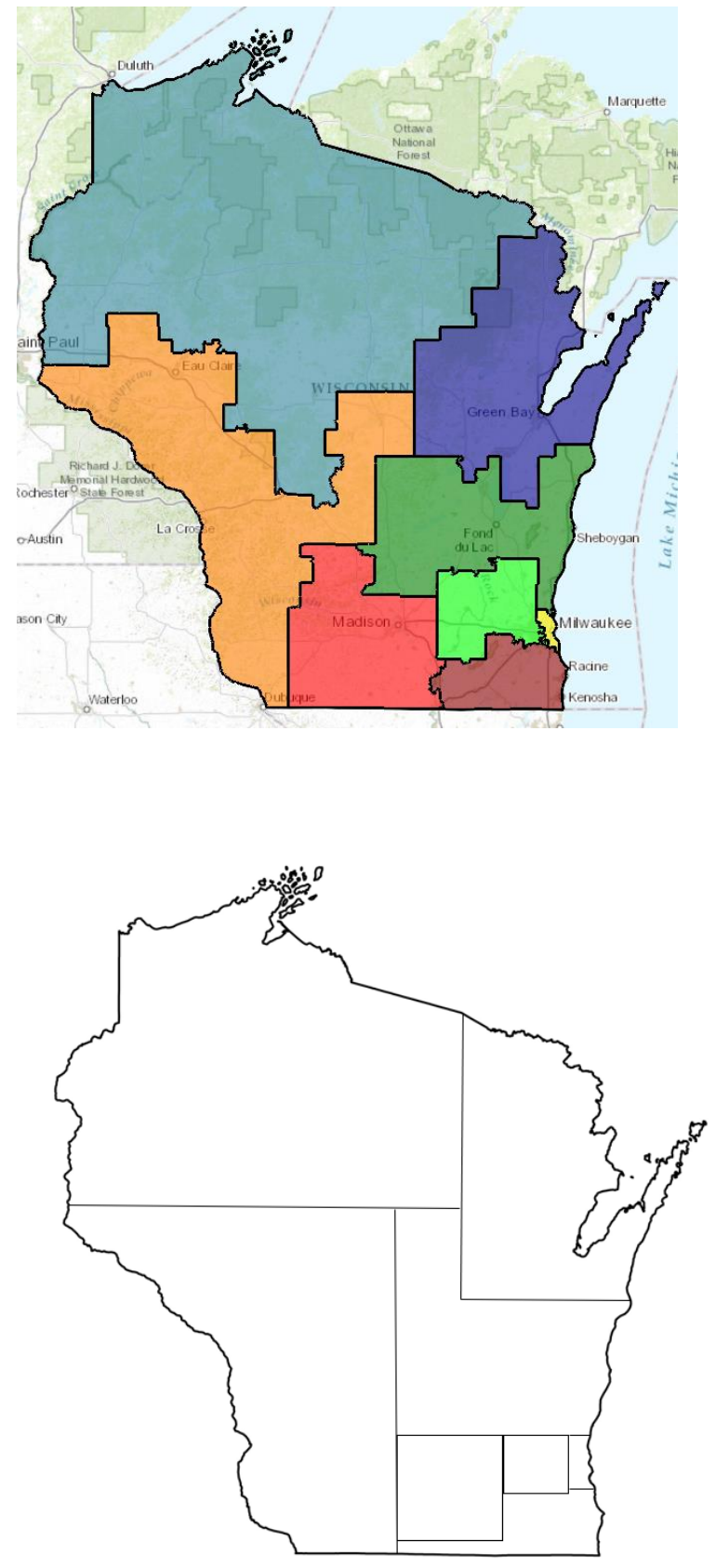
Partisan Fairness. The ultimate goal of redistricting is not simply to construct a legislative map made up of compact districts. The ultimate goal is to achieve partisan fairness. Scholars have explained the concept of partisan symmetry as a standard for partisan fairness:

The key to the symmetry definition of fairness is that it evaluates the electoral system as a whole by evaluating how voter preferences statewide are translated into the division of legislative seats between the parties. . . . The symmetry standard requires that the electoral system treat similarlysituated parties equally, so that each receives the same fraction of legislative seats for a particular vote percentage as the other party would receive if it had received the same percentage [of the vote]. Social scientists have long recognized partisan symmetry as the appropriate way to define partisan fairness in the American system of plurality-based elections (Grofman and King 2007 pp. 6-7).

This concept is starting to find its way into practice. In the Rucho decision, Justice Roberts references Section 3 of Article III of the Missouri Constitution as an example of the type of standards and guidance that states can provide for state courts to apply when addressing gerrymandering complaints. Passed overwhelmingly as a ballot initiative in 2018, this provision in the Missouri Constitution establishes the position of a non-partisan state demographer to draw legislative district maps and specifies: "[d]istricts shall be designed in a manner that achieves both partisan fairness and secondarily, competitiveness. Partisan fairness means that parties shall be able to translate their popular support into legislative representation with approximately equal efficiency"9 (Missouri Constitution).

In addition, in 2018, the Ohio Bipartisan Congressional Redistricting Commission qualified a ballot initiative which stated, in part,

The Ohio redistricting commission shall maximize representational fairness by adopting a plan whose statewide proportion of districts most closely corresponds to the partisan preferences of voters of Ohio as measured by the statewide proportion of votes in state and federal partisan statewide general

\footnotetext{
${ }^{9}$ The demographer shall develop an index based on past electoral performance of the two major parties and calculate "wasted votes." The difference between the two parties' wasted votes as a percentage of total votes shall be as close to zero as practicable.
} 
election results during the previous ten years. ${ }^{10}$ (Ohio Bipartisan

Redistricting Commission Amendment, Issue 1, 2015.)

NCSL reports that 19 states prohibit the drawing of legislative maps that intentionally favor or disfavor an incumbent, candidate or party (NCSL 2019). Furthermore, the tie-breaking chairman of New Jersey's Commission on Redistricting used partisan fairness as the main criterion for producing a fair legislative district map (Hirsch 2003).

The procedure described in this article employs a three-step process to construct legislative maps that are partisan fair. Step one constructs the set of compact districts as described above. Step two determines the statewide share of past votes between the two major parties in the state. The metric used was a composite index of the votes for the 2012 and 2016 Presidential elections, the 2016 and 2018 Senate elections, and the 2018 elections for Governor and Attorney General (from Bradlee and others, 2020). (Any votes for a third-party candidate were distributed proportionally between the two major parties.) Step 3 accommodates the geographic distribution of voters by adjusting some district lines, as needed, so each of the major party's likely share of seats most closely corresponds to its statewide share of past votes. The goal is to preserve compact districts while achieving partisan fairness.

Results. The table below summarizes the consequences of redistricting congressional districts based on nested squares and partisan fairness. The states are ordered by the percent of districts changed as a result of redistricting based on this procedure. The entries represent the expected number of seats for each party. "Goal" is calculated by multiplying statewide share of past votes for each party by the number of congressional districts in the state and rounding to the nearest whole number. "Current" represents the distribution across parties of the partisan lean of the current map (as of 2020) (Wikipedia). "Foundation" represents the expected distribution of seats from the map of compact districts made up of nested squares. These maps are displayed in Appendix B. "Partisan Fairness" represents the expected distribution of seats after applying the concept of partisan symmetry and adjusting some district boundaries to achieve partisan fairness. These maps are displayed in Appendix C.

${ }^{10}$ The initiative was withdrawn when the state legislature passed and voters approved an alternative plan. 
Table 1. ACHIEVING PARTISAN FAIRNESS

\# of Districts with Majority of Votes by Party

State Status Democrat Republican

\begin{tabular}{|l|l|l|l|}
\hline Ohio & Goal & 8 & 8 \\
\hline & Current & 4 & 12 \\
\hline & Foundation & $3(1$ even $)$ & 12 \\
\hline & Partisan Fairness & 8 & 8 \\
\hline
\end{tabular}

\begin{tabular}{|l|l|l|l|}
\hline Maryland & Goal & 5 & 3 \\
\hline & Current & 7 & 1 \\
\hline & Foundation & $6(1$ even $)$ & 1 \\
\hline & Partisan Fairness & 5 & 3 \\
\hline
\end{tabular}

\begin{tabular}{|l|l|l|l|}
\hline Mississippi & Goal & 2 & 2 \\
\hline & Current & 1 & 3 \\
\hline & Foundation & 0 & 4 \\
\hline & Partisan Fairness & 2 & 2 \\
\hline
\end{tabular}

\begin{tabular}{|l|l|l|l|}
\hline North Carolina & Goal & 6 & 7 \\
\hline & Current & 3 & 10 \\
\hline & Foundation & $\mathbf{6}$ & $\mathbf{7}$ \\
\hline & Partisan Fairness & 6 & 7 \\
\hline
\end{tabular}

\begin{tabular}{|l|l|l|l|}
\hline Michigan & Goal & 7 & 7 \\
\hline & Current & 4 & 9 \\
\hline & Foundation & $\mathbf{7}$ & $\mathbf{7}$ \\
\hline & Partisan Fairness & 7 & 7 \\
\hline
\end{tabular}

\begin{tabular}{|l|l|l|l|}
\hline Connecticut & Goal & 3 & 2 \\
\hline & Current & 5 & 0 \\
\hline & Foundation & 5 & 0 \\
\hline & Partisan Fairness & 4 & 1 \\
\hline
\end{tabular}




\begin{tabular}{|l|l|l|l|}
\hline Wisconsin & Goal & 4 & 4 \\
\hline & Current & 2 (1 even) & 5 \\
\hline & Foundation & $\mathbf{4}$ & $\mathbf{4}$ \\
\hline & Partisan Fairness & 4 & 4 \\
\hline
\end{tabular}

\begin{tabular}{|l|l|l|l|}
\hline Louisiana & Goal & 2 & 4 \\
\hline & Current & 1 & 5 \\
\hline & Foundation & 1 & 5 \\
\hline & Partisan Fairness & 2 & 4 \\
\hline
\end{tabular}

\begin{tabular}{|l|l|l|l|}
\hline Georgia & Goal & 6 & 8 \\
\hline & Current & 4 & 10 \\
\hline & Foundation & 4 & 10 \\
\hline & Partisan Fairness & 6 & 8 \\
\hline
\end{tabular}

\begin{tabular}{|l|l|l|l|}
\hline Alabama & Goal & 3 & 4 \\
\hline & Current & 1 & 6 \\
\hline & Foundation & 0 & 7 \\
\hline & Partisan Fairness & 2 & 5 \\
\hline
\end{tabular}

\begin{tabular}{|l|l|l|l|}
\hline Virginia & Goal & 6 & 5 \\
\hline & Current & 5 & 6 \\
\hline & Foundation & $\mathbf{6}$ & $\mathbf{5}$ \\
\hline & Partisan Fairness & 6 & 5 \\
\hline
\end{tabular}

\begin{tabular}{|l|l|l|l|}
\hline Texas & Goal & 15 & 21 \\
\hline & Current & 13 & 23 \\
\hline & Foundation & 11 & 25 \\
\hline & Partisan Fairness & 15 & 21 \\
\hline
\end{tabular}

In each of the twelve states studied, the procedure moved the distribution of partisan lean across districts toward partisan fairness. In four states, North Carolina, Michigan, Wisconsin and Virginia, complete partisan fairness was achieved in the first step by constructing a foundational map of compact districts made up of nested squares. In six states, Ohio, Maryland, Mississippi, Louisiana, 
Georgia, and Texas, the nested squares map formed a foundation, and the principle of partisan symmetry was employed to achieve partisan fairness. In two states, Connecticut and Alabama, the procedure produced compact districts and moved the current distribution of partisan lean toward partisan fairness. ${ }^{11}$

\section{ADMONITION}

During oral arguments in the Gill gerrymandering case, Chief Justice Roberts commented on using the "efficiency gap," a measure of "wasted votes," to describe the degree of partisan gerrymandering. Referring to this measure as "EG," he cautioned:

[If] you're the intelligent man on the street and the court issues a decision, and let's say, okay, the Democrats win, and that person will say: "Well, why did the Democrats win?" And the answer is going to be because EG was greater than 7 percent, where EG is the sigma of party $\mathrm{X}$ wasted votes minus the sigma of party $\mathrm{Y}$ wasted votes over the sigma of party $\mathrm{X}$ votes plus party $\mathrm{Y}$ votes. And the intelligent man on the street is going to say that's a bunch of baloney. It must be because the Supreme Court preferred the Democrats over the Republicans. And that's going to come out one case after another as these cases are brought in every state. And that is going to cause very serious harm to the status and integrity of the decisions of this court in the eyes of the country (Gill, p.37).

The sentiment of Justice Robert's admonition is that the typical thoughtful citizen is most likely to support a finding if he or she understands the underpinnings of the decision.

That same sentiment applies to redistricting approaches. Some might argue that using statewide vote share as the foundation for defining partisan fairness is too simplistic, preferring instead sophisticated statistical modeling. Some might prefer elegant computer algorithms or mathematical models rather than a transparent approach that can be done by hand. This article presents a straightforward transparent approach to nonpartisan redistricting that deliberately sacrifices sophisticated statistical modeling and computer elegance in favor of promoting public understanding and support.

\footnotetext{
${ }^{11}$ In these two states the distribution of voters precluded a map of compact districts achieving complete partisan fairness. The procedure chosen here preserved compact districts at the expense of achieving total partisan fairness. In such instances, mapmakers might choose instead to achieve total partisan fairness at the expense of compact districts.
} 


\section{STATE LIGISLATURES}

This section of the article provides an example of how this process can be used to redistrict the map for a state legislative body. The composite measure used throughout this article shows statewide shares of past votes in Wisconsin of $51.3 \%$ for Democrats $48.7 \%$ for Republicans. Gilbert (2018) reports that the current map for the Wisconsin State Assembly yields a partisan lean in state Assembly districts of 64-35 in favor of the Republicans.

Figure 2 presents the map generated by using nested squares and partisan fairness for the Wisconsin State Assembly.

Figure 3. Partisan Fair Legislative Map Wisconsin State Assembly

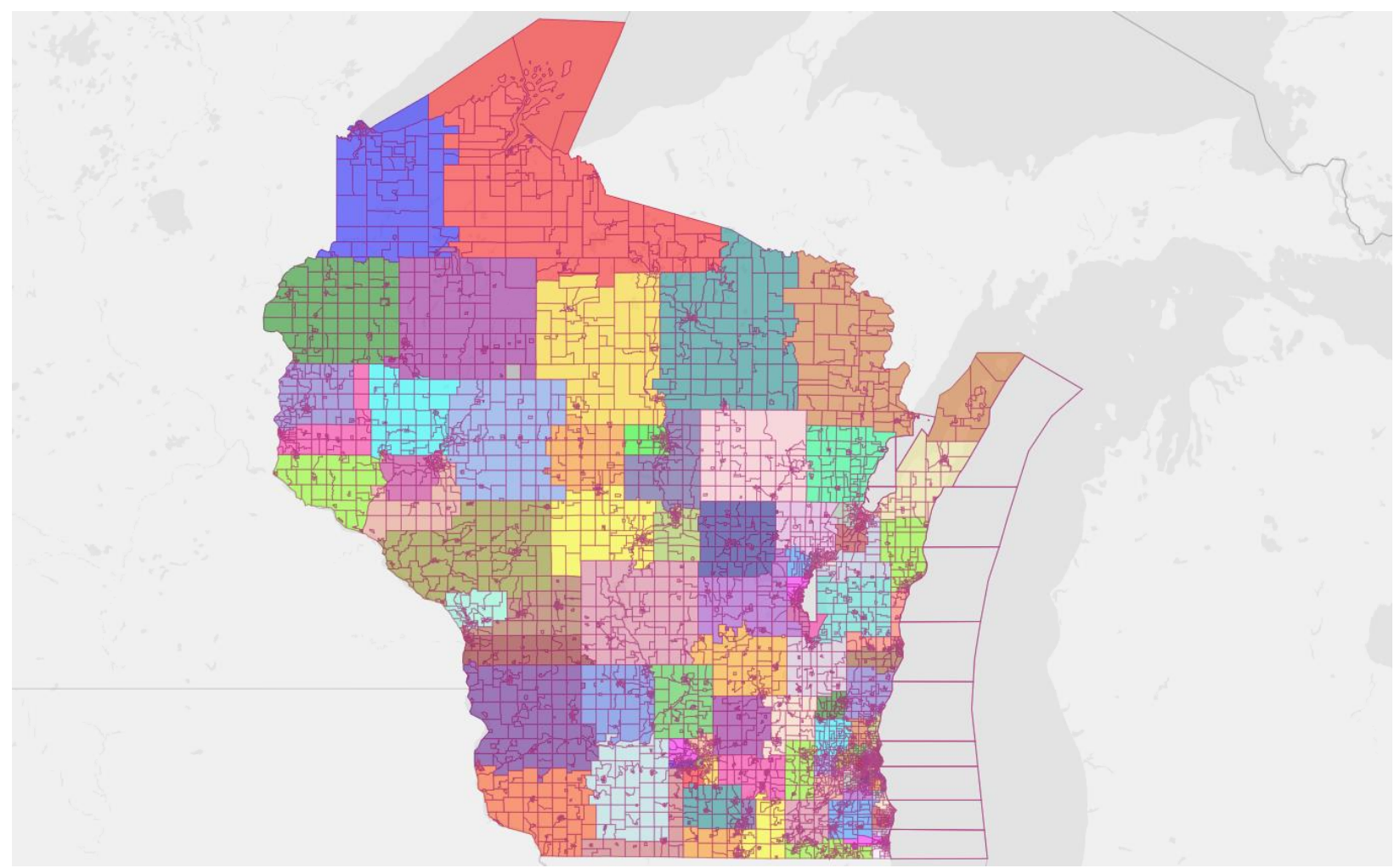

The distribution of Wisconsin State Assembly seats that is proportional to the statewide share of votes is 51 Democrats and 48 Republicans. In the map above, Democrats have the majority partisan lean in 51 districts and Republicans have the majority partisan lean in 48 districts. 


\section{ADDRESSING POSSIBLE CONCERNS}

Concern: Hypotheticals such as past votes in a district should not be used. Past voting in a district predicts very well which party will win that district in the next election. Rakich (2018) examined all contests for the U.S. House of Representatives in the 2018 election. He found that for all districts for which there was at least one Democrat and one Republican candidate, the correlation between partisan lean and vote margin in a district was 0.98 .

Gerrymanderers understand this and use past votes as the foundation of their gerrymandered maps. Justice Kagan in her Rucho dissent (p. 17) notes:

North Carolina's redistricting committee used 'Partisan Advantage' as an official criterion for drawing district lines. And from first to the last, the committee's chair (along with his mapmaker) acted to ensure a 10-3 partisan split, whatever the statewide vote, because he thought electing Republicans is better than electing Democrats.

Gerrymanderers use the powerful tool of distributing past votes among legislative districts to tilt the playing field. The approach advanced in this article uses this tool to level the playing field.

Concern: Proportionality should not be used. Justice Roberts in his Rucho opinion invokes Justice O'Connor's decision in Bandemer "Our cases, however, clearly foreclose any claim that the Constitution requires proportional representation or that legislatures in reapportioning must draw district lines to come as near as possible to allocating seats to the contending parties in proportion to what their anticipated statewide vote will be" (p. 130).

However, Justice Roberts also clearly distinguishes what is judiciable in Federal court vs. State courts. He states that "[p]rovisions in state statutes and state constitutions can provide standards and guidance for state courts to apply. He notes that the Federal Constitution contains no "Fair Districts Amendment," but "the Supreme Court of Florida struck down that state's congressional districting plan as a violation of the Fair Districts Amendment to the Florida Constitution (Rucho p. $31)$.

Justice Roberts also references the Missouri Constitution, Art. III, Section 3 as an example of a state's action to restrict partisan considerations in districting. As noted above, this provision states: "Partisan fairness means that parties shall be able to translate their popular support into legislative representation with approximately equal efficiency." 
Furthermore, importantly, the approach advanced in this article does not allocate actual seats to correspond with past party shares of statewide votes. Rather the approach allocates the distribution of partisan lean across districts. No voter outcomes are guaranteed. The playing field is simply leveled.

In addition, Katz, King and Rosenblatt (2019, p. 10) prove that deviation from proportional representation is an inadequate measure of partisan symmetry. This article does not dispute that. However, the method used here of combining compact districts with partisan symmetry generates a set of districts, a complete legislative plan, which in turn can be used to generate a seats-vote curve. The deliberate process of adjusting the nested squares map to a partisan fair map reshapes the seats-vote curve such that the curve for each party crosses the 45degree line at that point where the expected share of seats for each party corresponds with that party's share of statewide votes.

Concern: The procedure does not focus explicitly on preserving political subdivisions. Because of the requirement for equal population in districts, no congressional district map will perfectly match the boundaries of existing political subdivisions Districts in sparsely populated areas are likely to contain several counties. Densely populated counties may contain more than one congressional district. Because the nested squares procedure generates compact districts, it tends to preserve political subdivisions.

Concern: Communities of interest should be maintained. This procedure maintains communities of interest because it constructs compact districts. Compact districts preserve communities of interest. To a large extent, neighborhoods tend to form communities of interest. For example, the residents of Brooklyn form a community of interest different from the residents of Lower Manhattan. The residents of Boyle Heights form a community of interest different from that formed by the residents of Beverly Hills. As a result, compact districts contain communities of interest.

Concern: Districts should be bounded by natural borders such as rivers, streams, mountains and lakes. In the distant past, rivers, streams, mountains and lakes formed barriers to transportation. Modern infrastructure obviates this concern.

Concern: The goal of redistricting should be to construct competitive districts. Figure 3 is a congressional district map of Ohio where every district is competitive. Specifically, each district has a partisan lean that is close to the partisan lean of the state as a whole. This figure illustrates that for many districts, a geographic area with a high concentration of one party must be connected, often by tendrils, to an 
area with a high concentration of the other party in order to simultaneously satisfy the competitive criterion and the population requirements. As a result, districts are often not compact; one political subdivision of the state is often joined with another distant subdivision; and, the elected officials are unlikely to represent communities of interest.

Figure 4. Ohio Congressional Districts

Each District As Competitive As Whole State

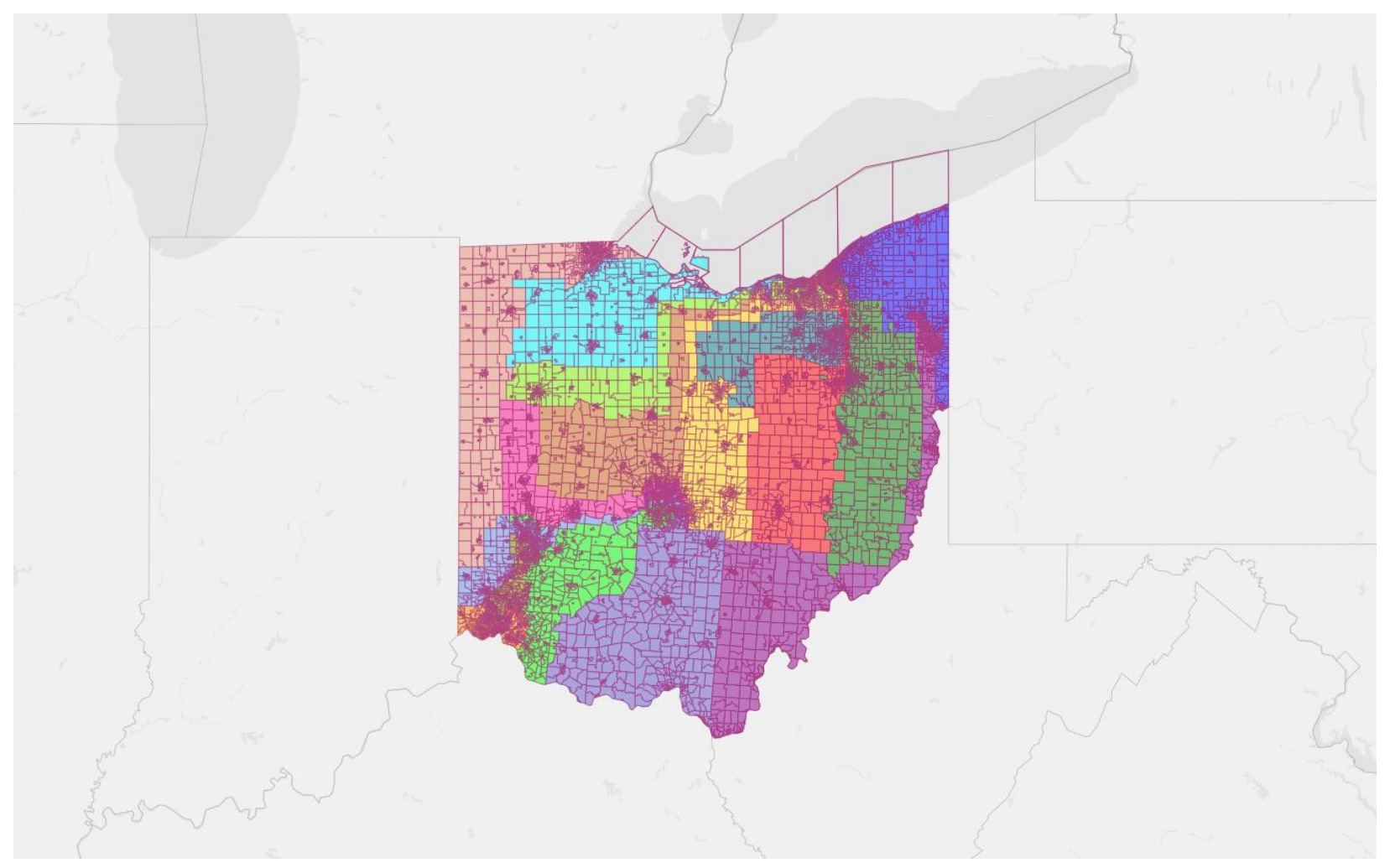

\section{SUMMARY AND CONCLUSIONS}

Legislative district maps will soon be redrawn in response to the 2020 census. Mapmakers, be they redistricting commissions, state demographers, legislative staff, or court appointed Masters, face a task more daunting than ever before. This 
article presents a straightforward, transparent, nonpartisan method for generating legislative district maps that contain compact districts and are are partisan fair.

The overwhelming majority of states require that legislative district maps be constructed of districts that are compact. A recent award-winning study revealed that citizens from all walks of life see districts that are "squarish" as being most compact. The procedure developed in this study generates maps that are made up of districts that are nested squares.

The procedure then builds on the map of compact districts to generate a map that is partisan fair. Partisan fairness is defined as when each major party's likely share of seats corresponds to that party's share of statewide votes. By uniting partisan fairness with compact districts, this procedure constructs legislative district maps that are fair and square.

\section{APPENDIX A: CONSTRUCTING NESTED SQUARES}

The Basic Procedure. The basic nested squares procedure follows:

(1) Start at the upper left of a state map and draw a square which expands to the right and down until the district contains the required population. Then move to the upper left corner of the unoccupied area and proceed from left to right (as we read in America). Produce a series of adjoining squares across the top of the map. (Note: portions of a square near a state boundary may extend beyond the boundary of the state. Those portions would contain no population within the state.) Whenever a square meets an already claimed area, "tuck" the new square under the existing square and readjust the size of the square to meet the population requirement. ("Claimed area" means that portion of the state that is contained by a district.)

The diagrams in this appendix draw upon the state of Georgia to illustrate how the nested procedure is implemented. Georgia happens to provide the opportunity to portray both the basic procedure and its three refinements. Diagram (a) below shows the first district constructed for Georgia. The red border of the square highlights that portion of the district which lies beyond the boundary of the state.

Diagram (b) shows the top row of districts for Georgia. The district on the farright in diagram (b) demonstrates the first refinement to the nested squares procedure. The basic procedure calls for constructing squares by moving along a diagonal down and to the right of the starting point. Thus, all portions of the 
resulting district will lie down and to the right of the starting point. A refinement to this procedure occurs when districts are constructed at the far-right of the state. Here, the district will be that square which contains the required population and whose right side just touches a portion of the right border of the state. On occasion, this will result in part of this district lying to the left of the starting point. This refinement achieves district compactness by avoiding long and narrow districts at the far right of a state.

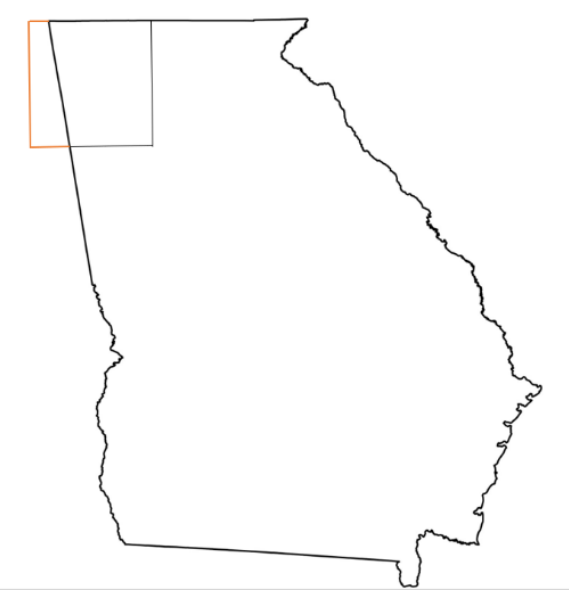

(a)

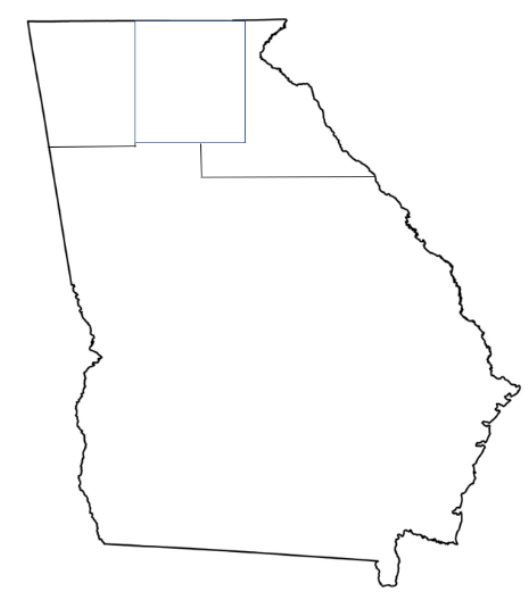

(b)

(2) Return to the upper left of the remaining unclaimed area in the state and repeat the process.

Chimneys. Before returning to the far left to start a new row in the basic procedure, occasionally a "chimney" shape will be encountered. A test should be run to see if a district started at the upper left of the chimney will fit within the chimney. That is, either the left or right side of the district in question is shorter than an adjoining district. (This test guards against any district wrapping around another district on three sides.) If so, that district should be constructed. If not, the new row should start from the far left of the map. Filling chimneys yields compact districts.

Diagram (c) below displays the top two rows of nested squares for Georgia. After the second row of districts is drawn, a "chimney" shaped area appears where the 
star is located. A test reveals that two districts can be constructed in this space where at least one side of each district would be completely covered by an existing district. These two new districts are displayed in diagram (d) as the districts with stars in them. These districts are formed before returning to the far left of the state to construct the next row.

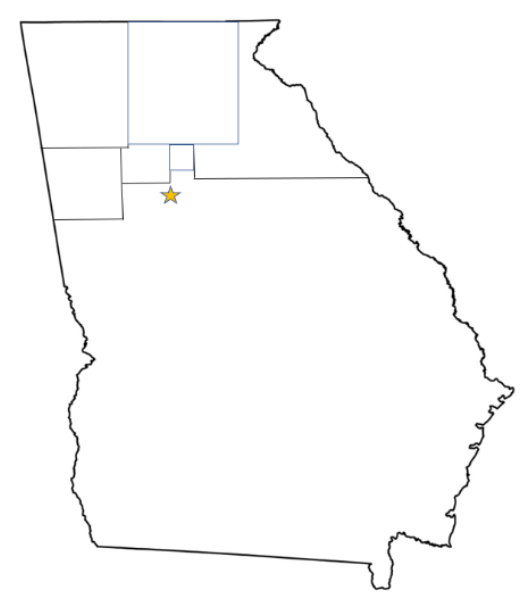

(c)

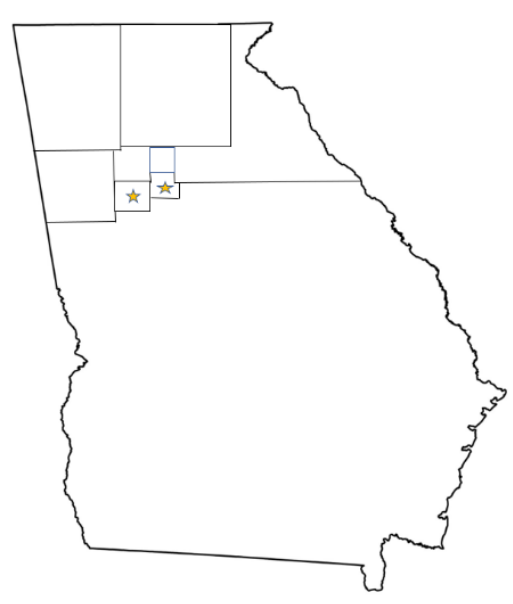

(d)

The final refinement comes into play whenever unclaimed space appears above a district under construction. Figure (e) below is a rendering of nested squares for Georgia where all three districts in the third row are drawn using the basic procedure before the final refinement. The red rectangle displays space between the far-right district in row 2 and the far-right district in row 3 . This space would not be included in any district under the basic procedure. This final refinement states that whenever unclaimed space appears above a district under construction, that district is moved up to include that unclaimed area. Figure (f) includes the third row of Georgia districts constructed by employing this final refinement. Each of the three districts in this row have been moved up to capture unclaimed area. 


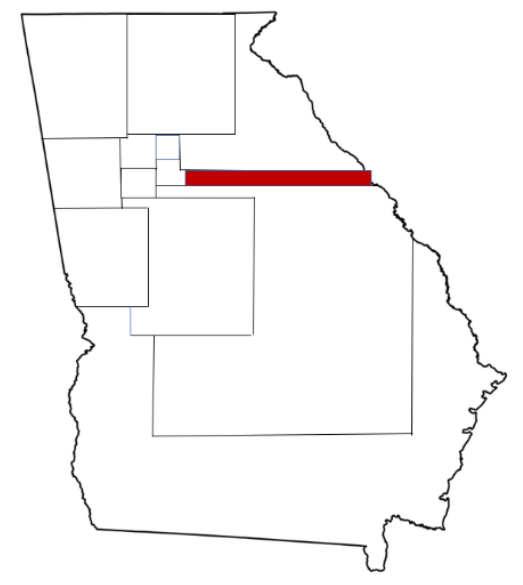

(e)

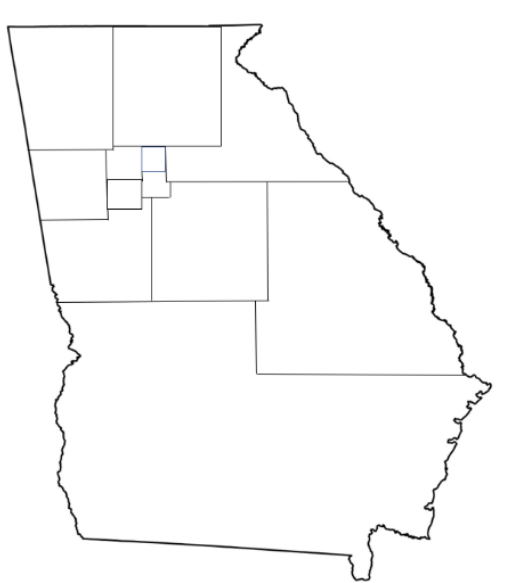

(f)

Extremities. Some states contain geographical extremities, such as Maryland's Eastern Shore, Michigan's Upper Peninsula, or the Texas Panhandle. Whenever extremities appear, the standard procedure might generate individual districts that are substantially disjoint or substantially not compact. This can be remedied by initially finding that longitude or latitude that forms the extremity, in whole or in part, into a district unto itself. Then apply the standard procedure to the remainder of the state.

The diagrams below illustrate how this initial step was applied to Maryland, Michigan, Texas and Virgina.

MARYLAND

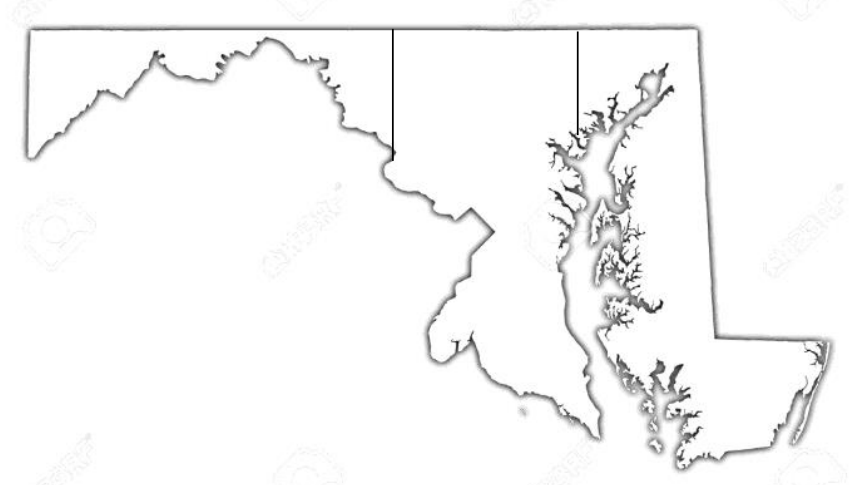

MICHIGAN

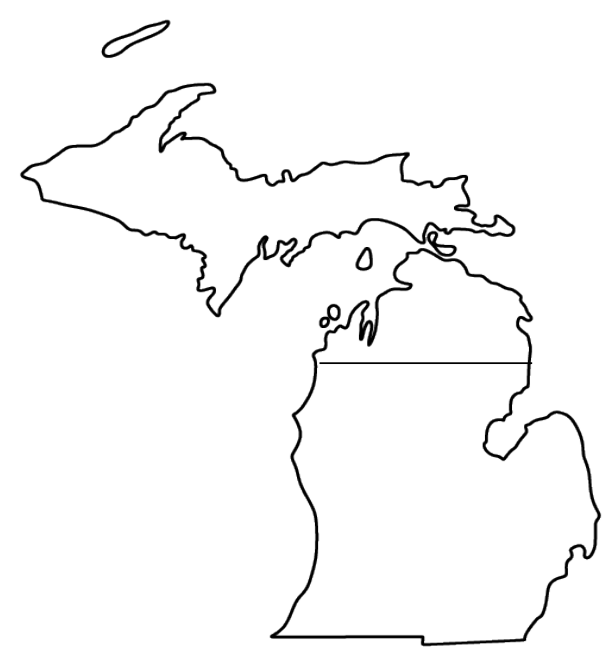


TEXAS

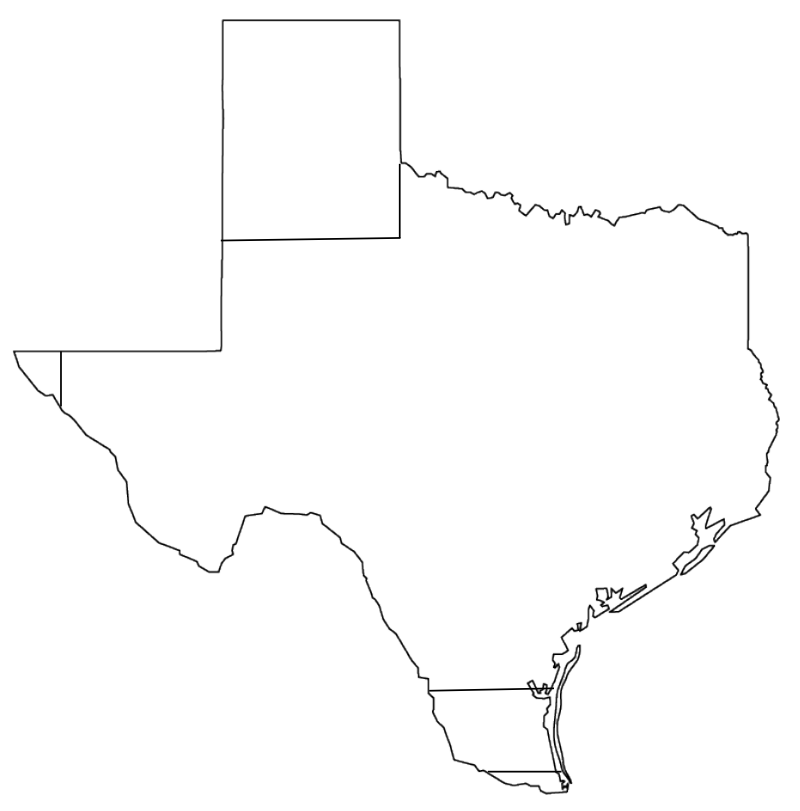

VIRGINIA

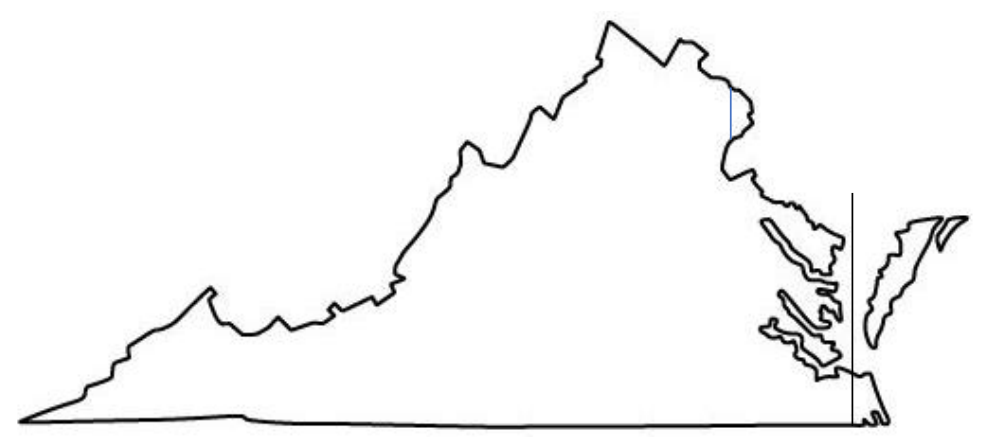

Summary. To construct a legislative district map composed of compact nested square districts:

(1) Start at the upper left side of the state and construct a square district moving on a diagonal down and to the right until you have contained the required population.

(2) Move to the next upper left corner and repeat, to construct a row of districts across the top of the state.

(3) Move to the far left of the unclaimed area in the state and repeat, constructing row after row of nested square districts.

(4) When constructing the farthest right district in a row, move that district to the left until the right side of the district just touches the right boundary of the state. 
(5) Fill any chimneys.

(6) Whenever unclaimed area appears above a district under construction, move that district up to contain that unclaimed area.

(7) If a state has extremities, construct districts there prior to moving to the remainder of the state.

\section{APPENDIX B: COMPACT DISTRICT MAPS}

Shown below are the legislative district maps which contain compact districts constructed by nested squares. The district lines in these maps are not as straight as in the conceptual renderings because precincts at the edges of the districts are added on an all or none basis. For each state, the population variance among the districts is within the judicial standard. The maps will be published on DRA. (Bradlee and others, 2020).

\section{ALABAMA}

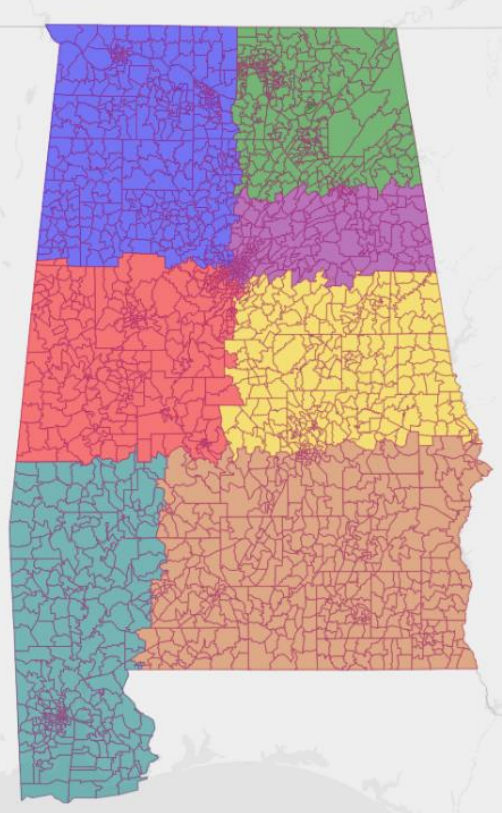




\section{CONNECTICUT}

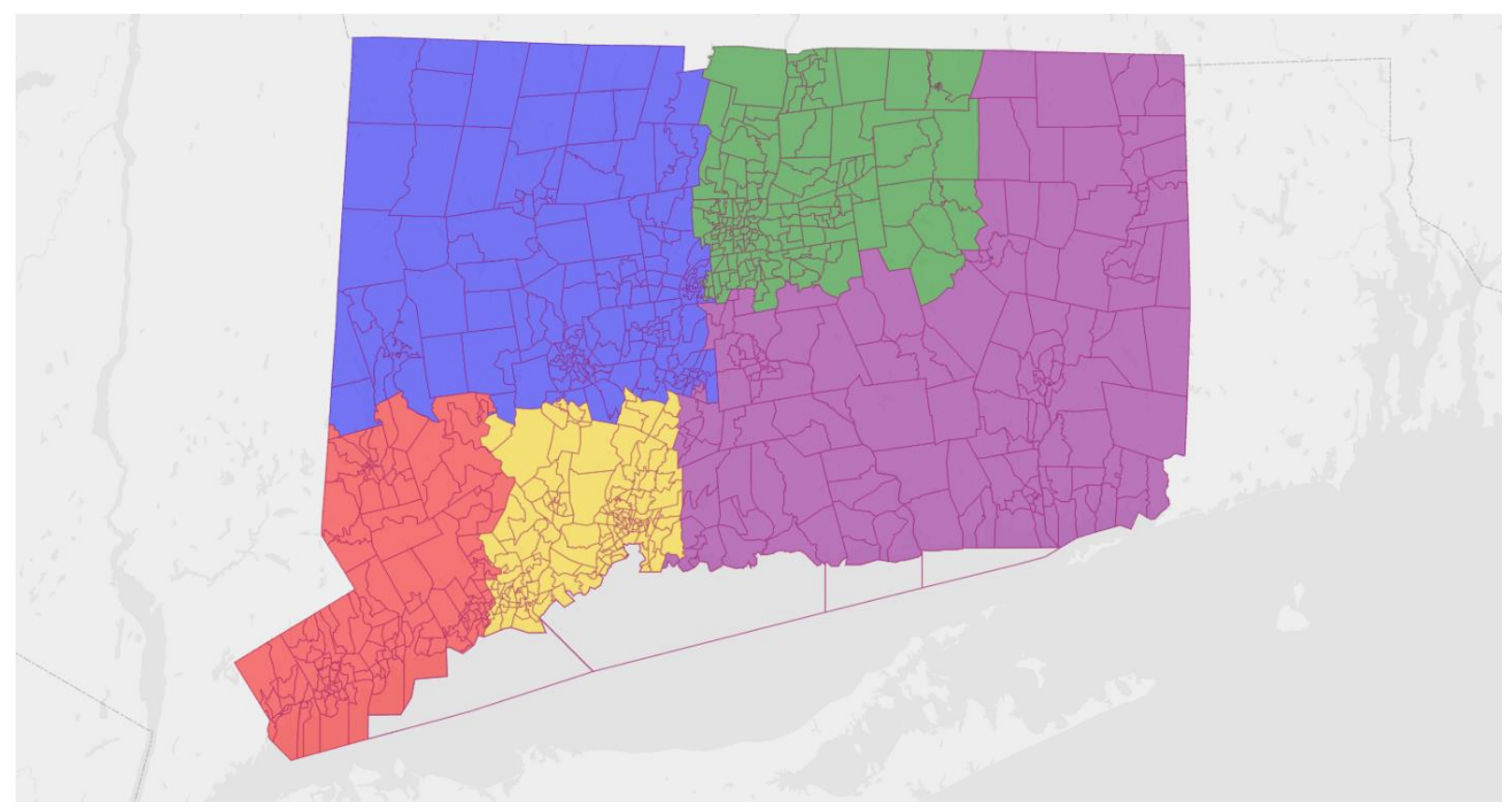

GEORGIA

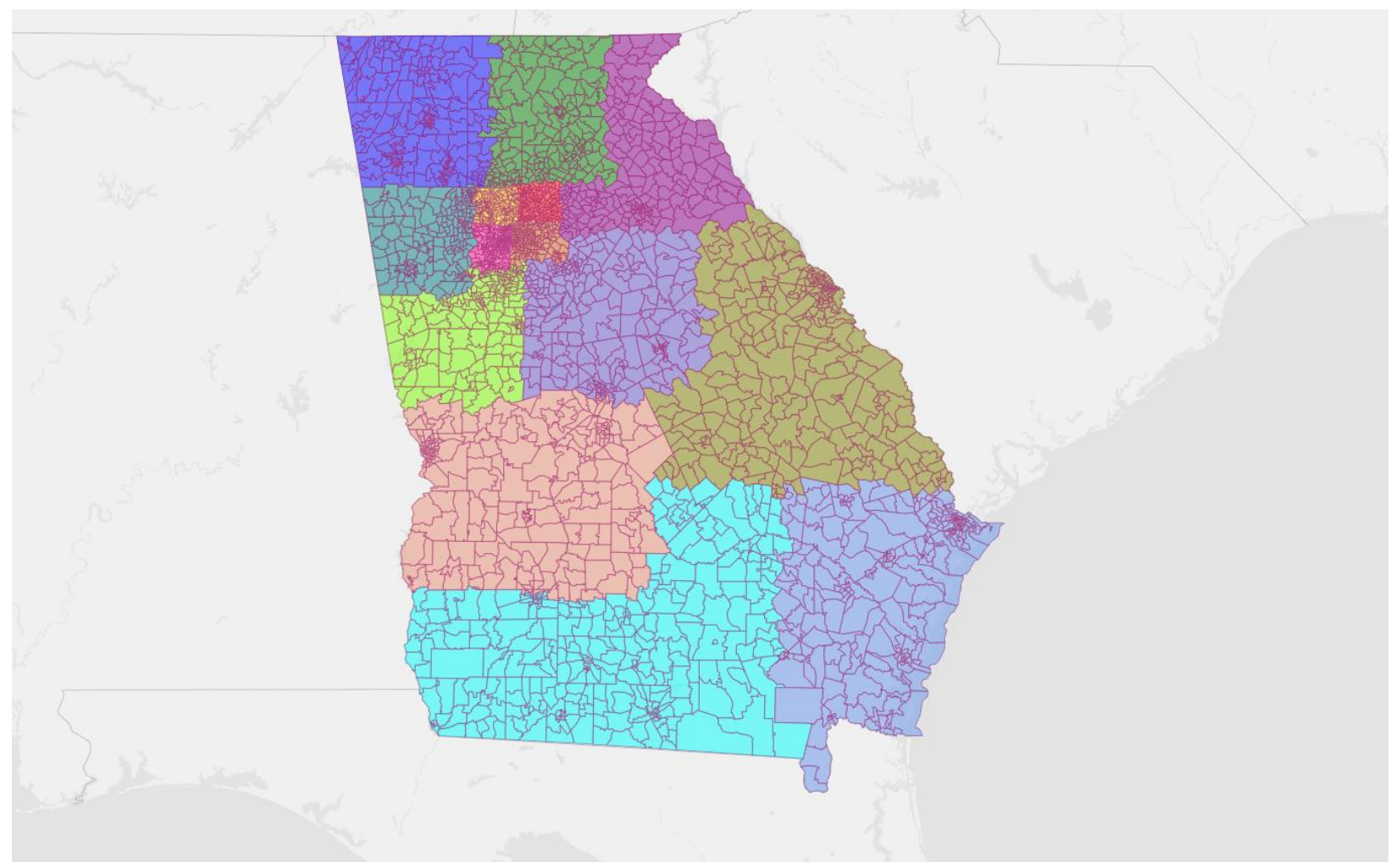




\section{LOUISIANA}

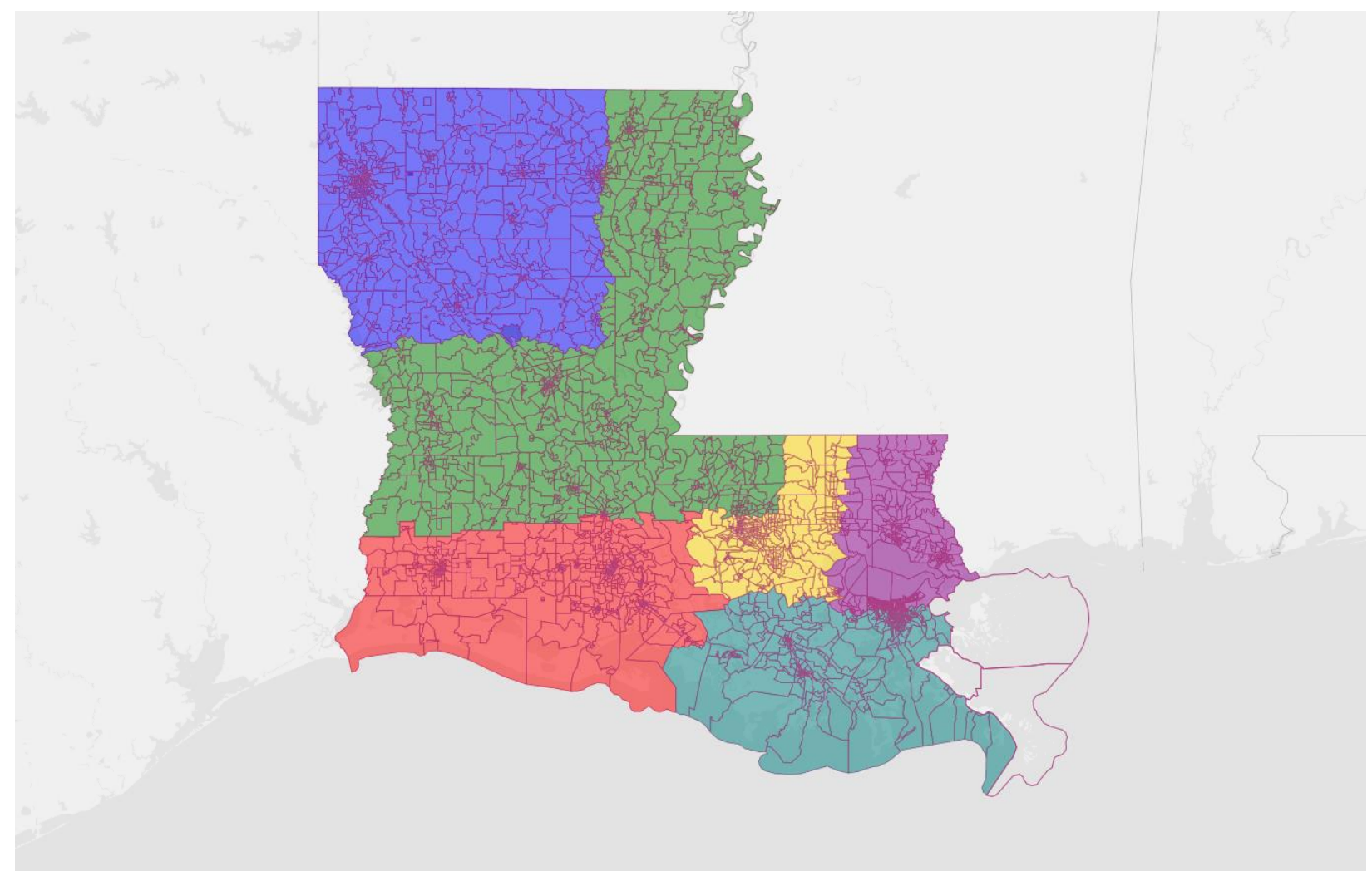

\section{MARYLAND}

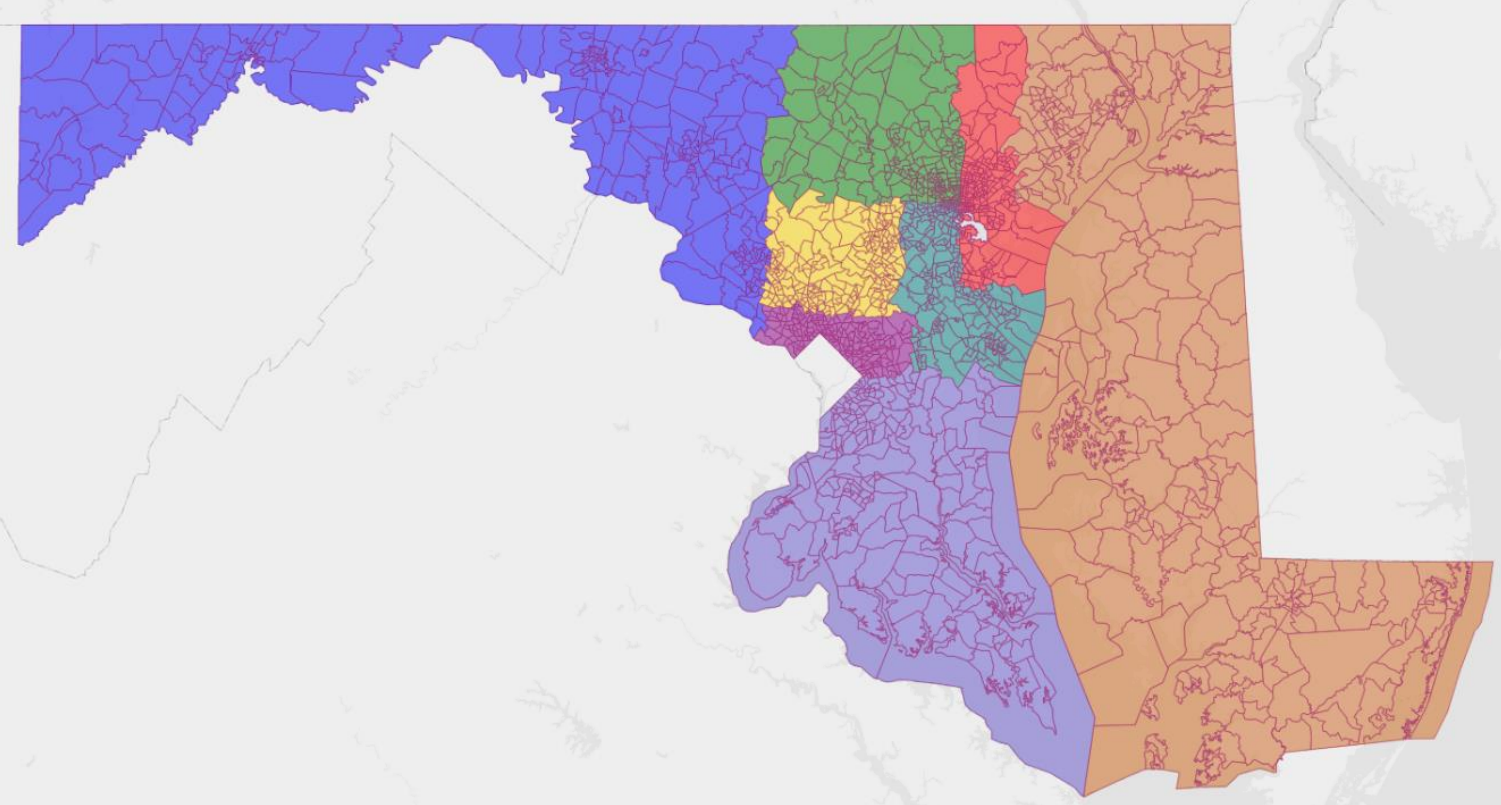




\section{MICHIGAN}

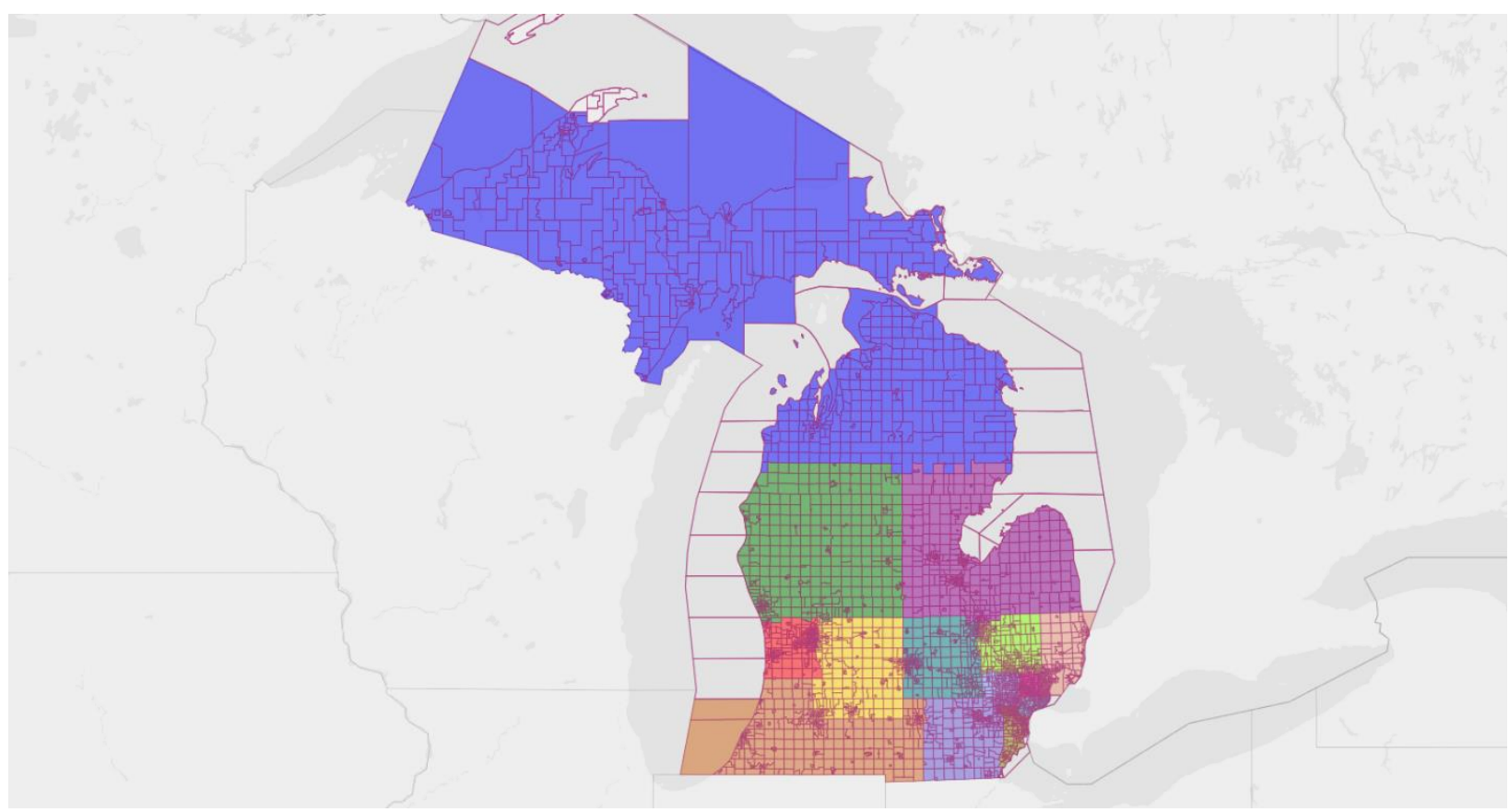

MISSISSIPPI

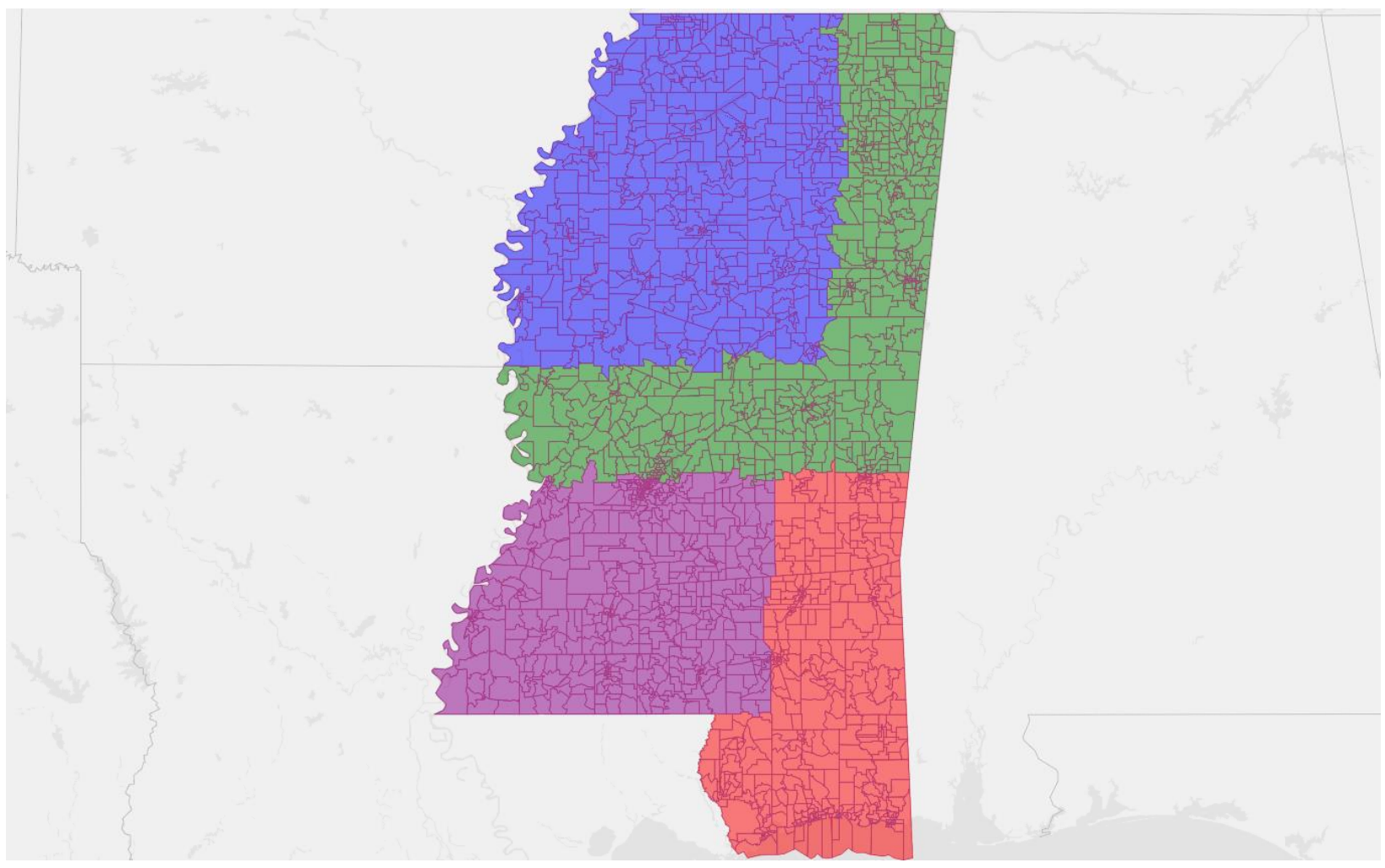


NORTH CAROLINA

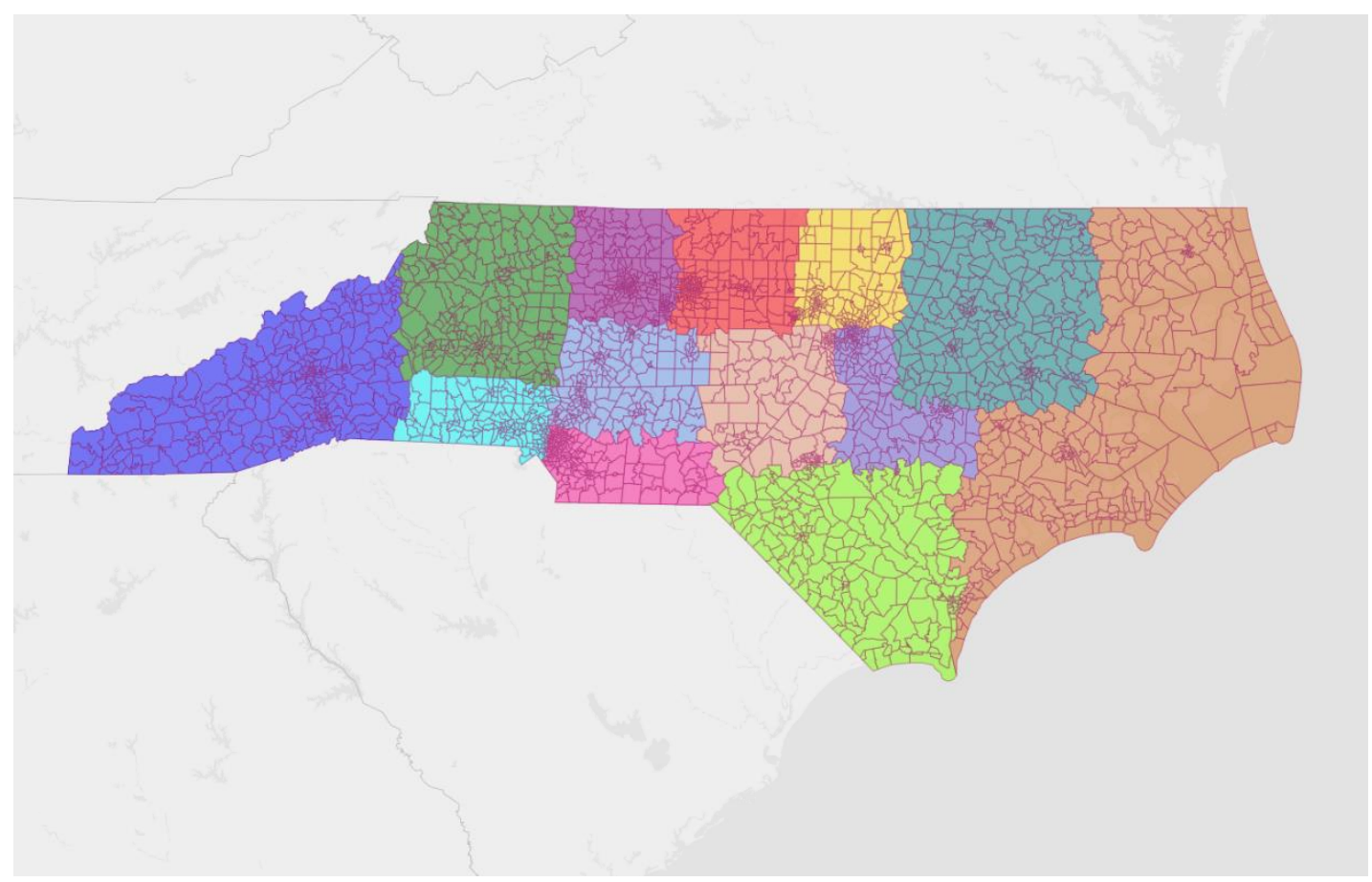




\section{OHIO}

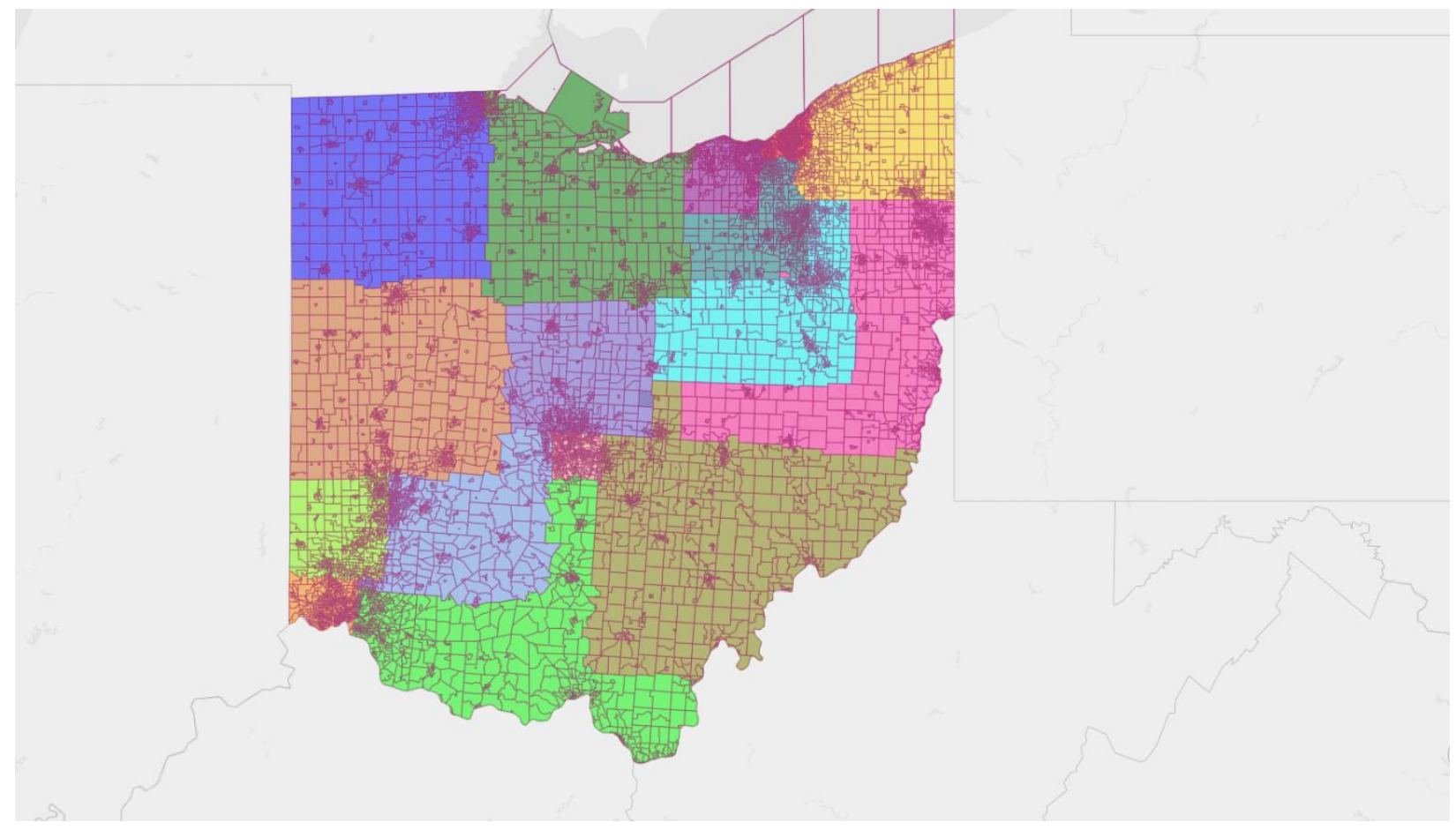

TEXAS

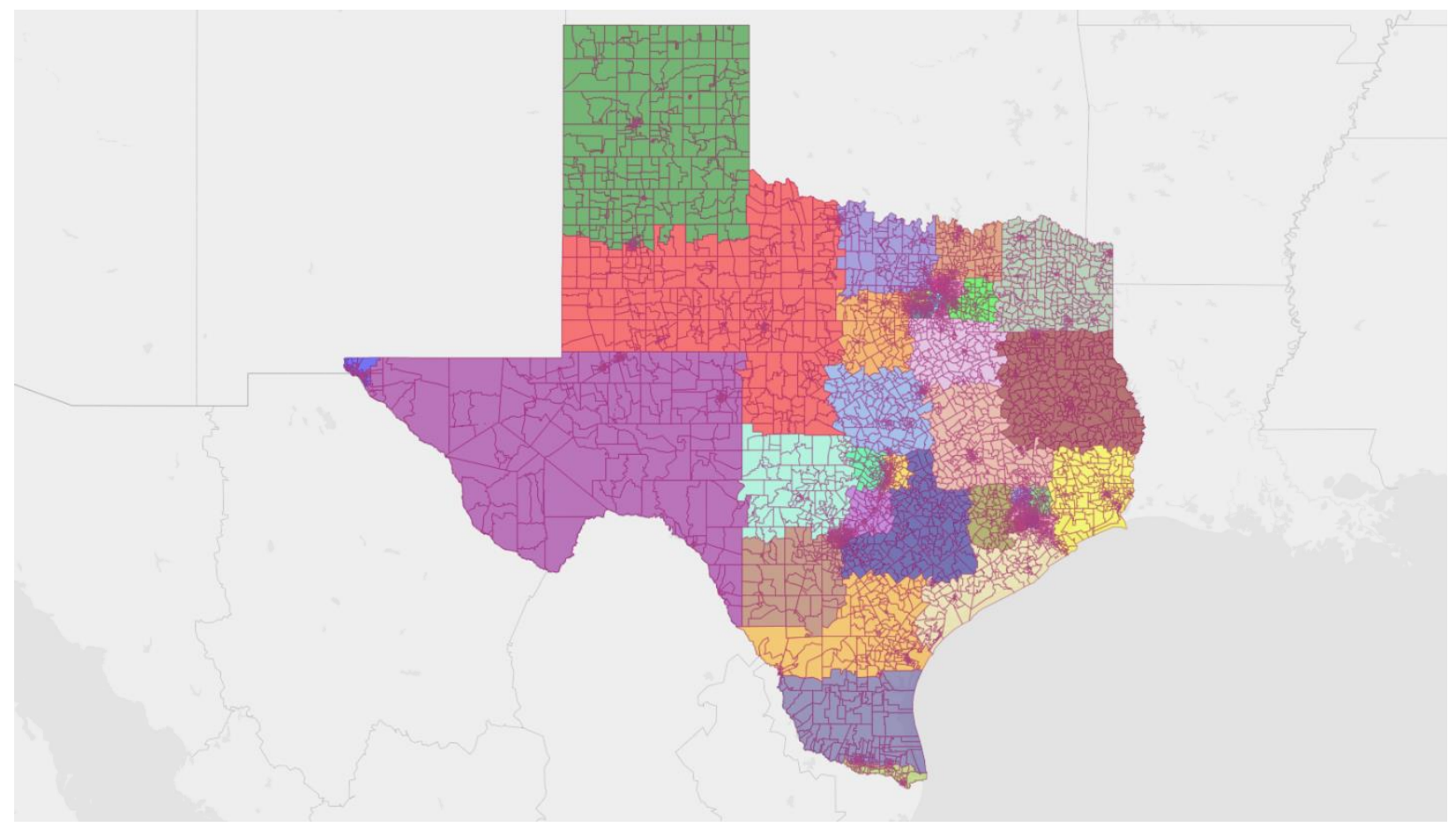




\section{VIRGINIA}

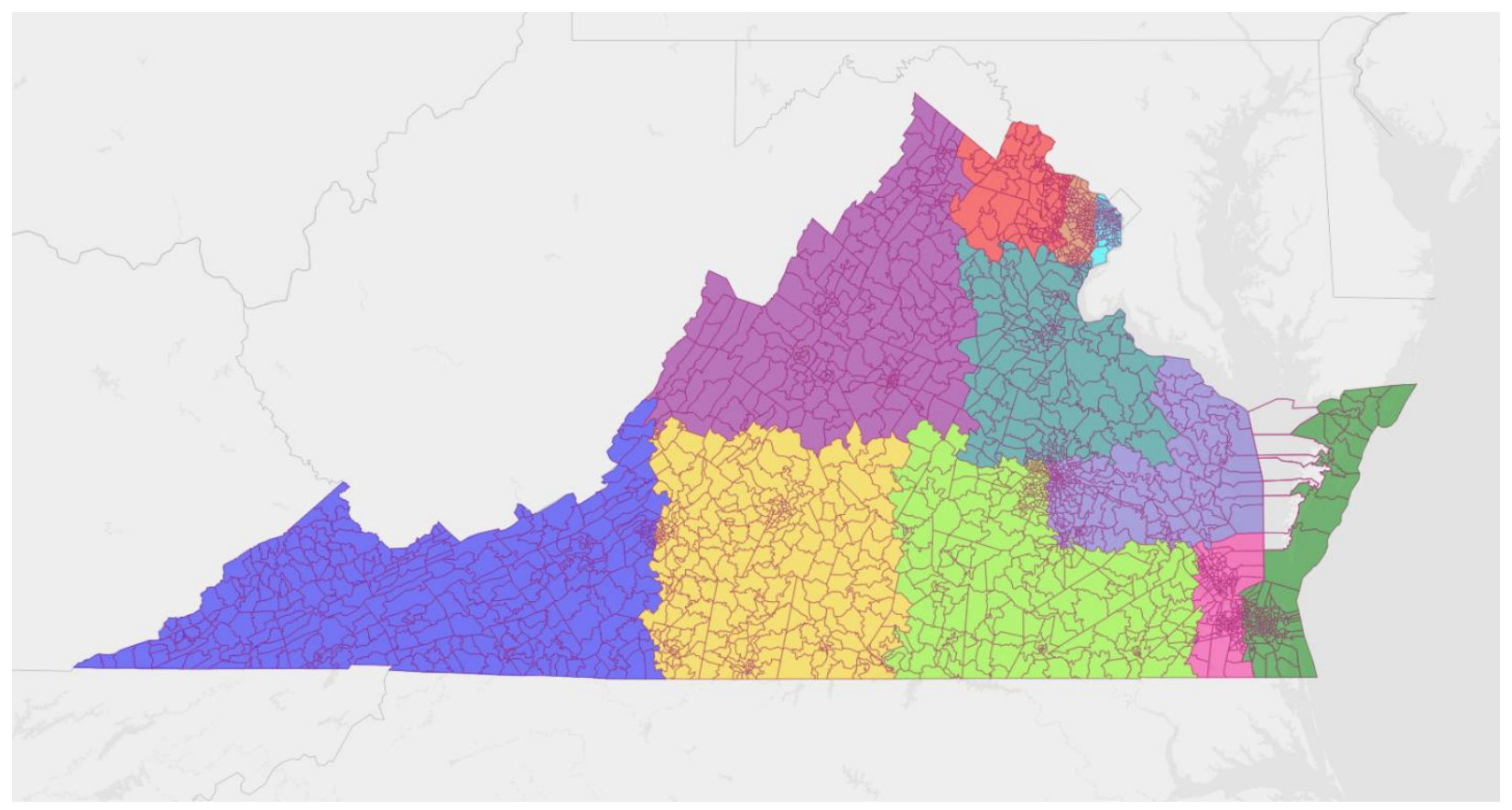

WISCONSIN

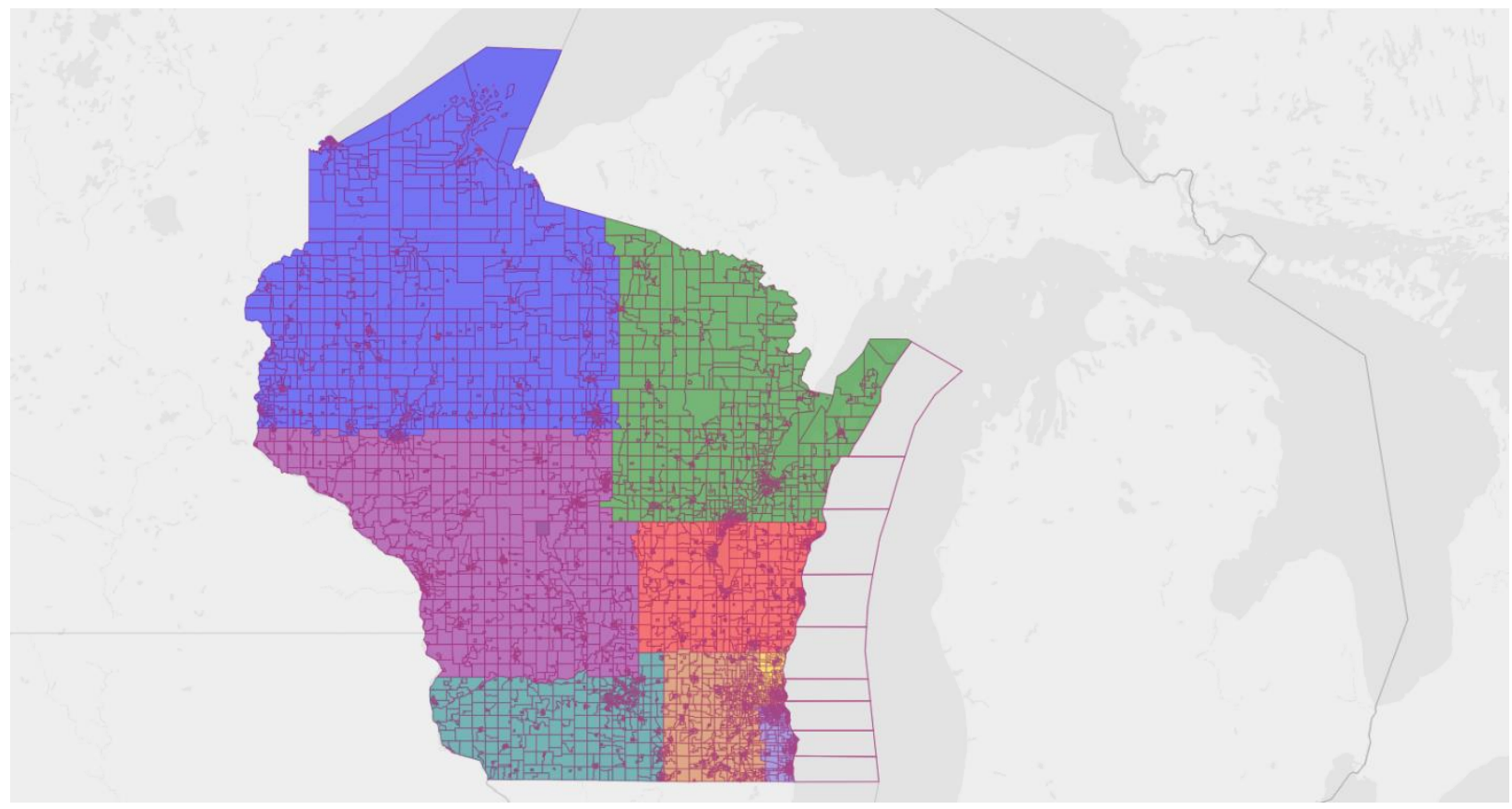




\section{APPENDIX C: PARTISAN FAIR MAPS}

As noted above, in four states, the nested squares map contained compact districts and was partisan fair. Shown below are the maps of the remaining eight states where the concept of partisan symmetry was applied.

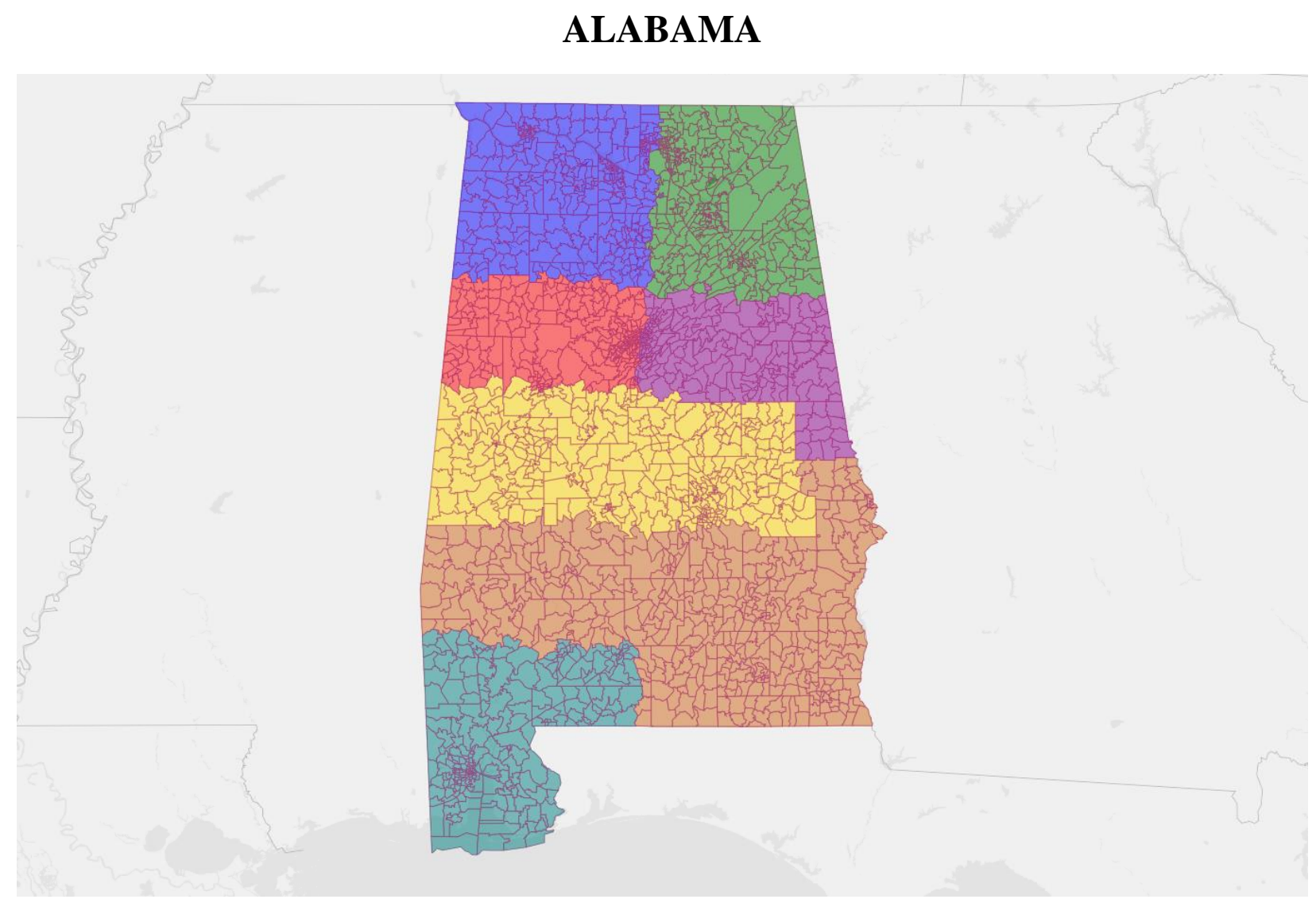




\section{CONNECTICUT}

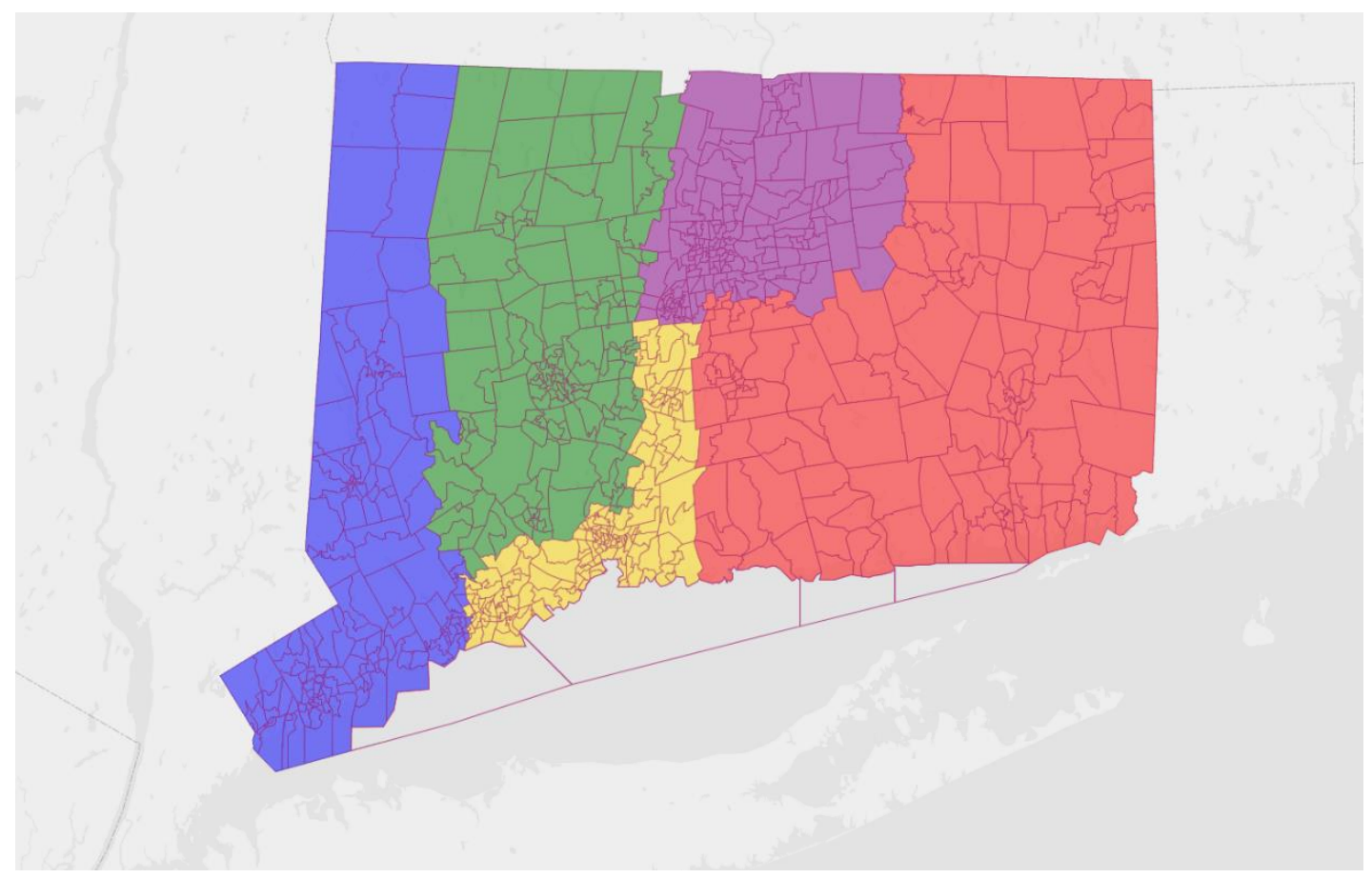

GEORGIA

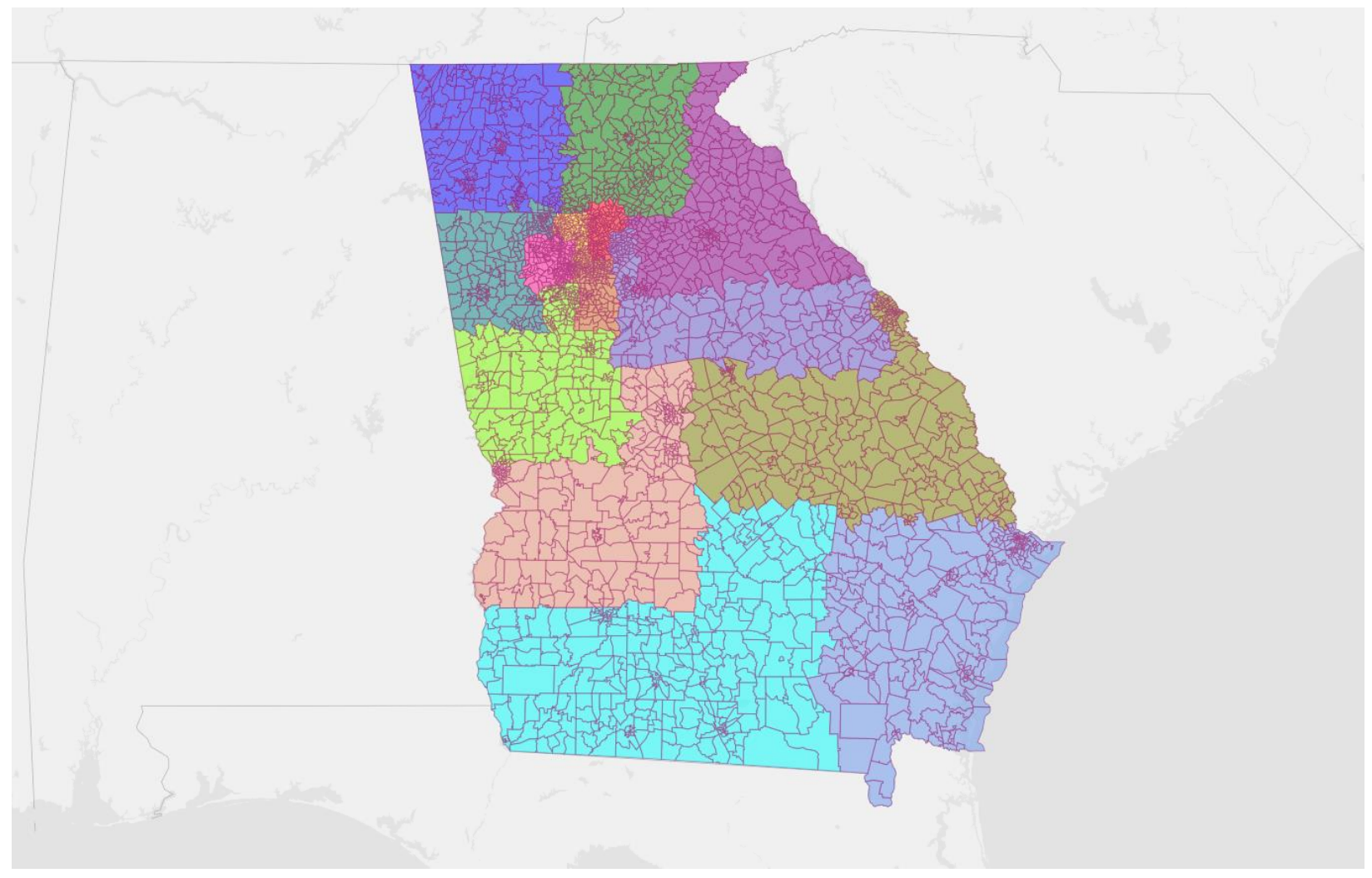




\section{LOUISIANA}

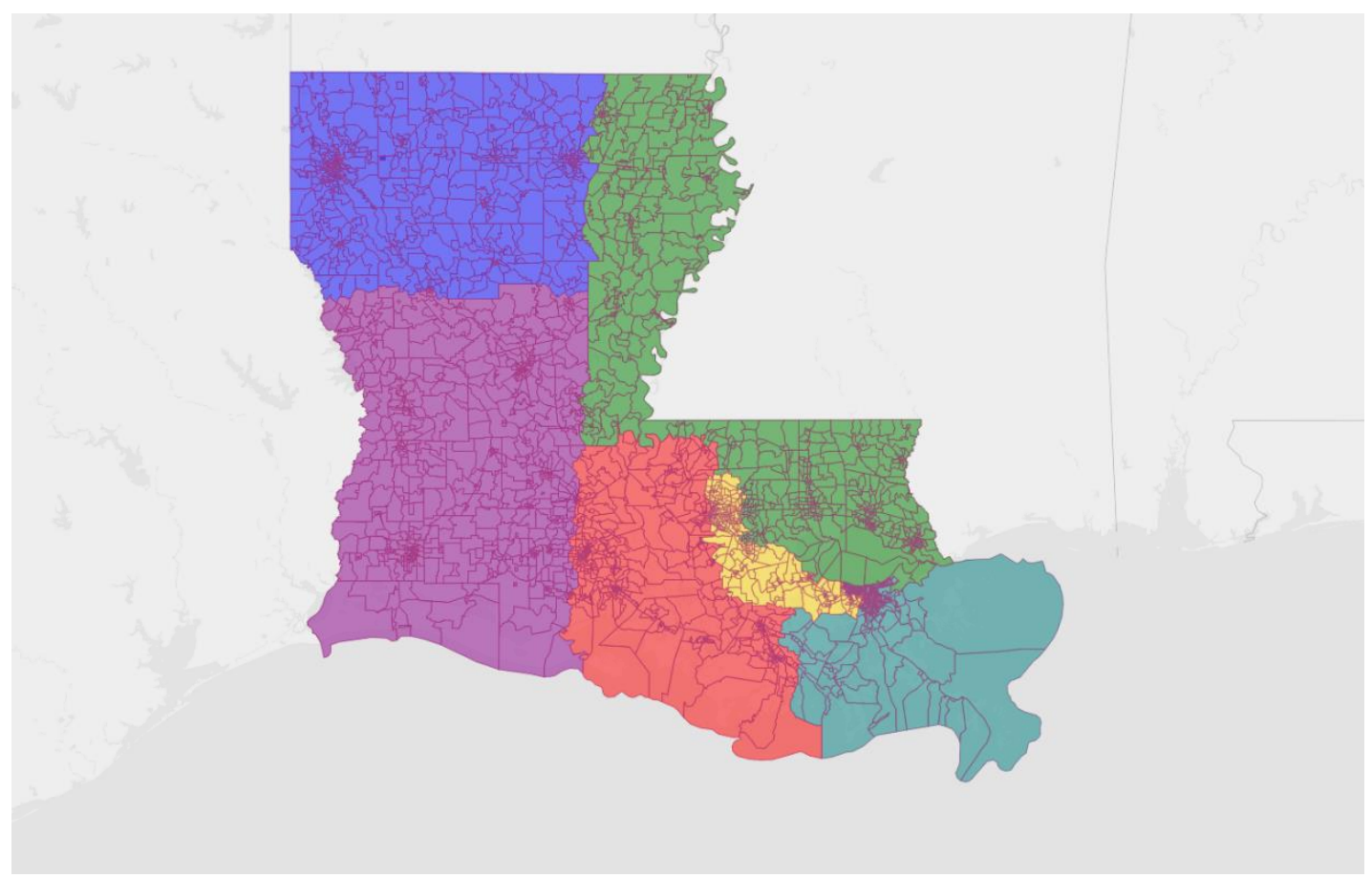

\section{MARYLAND}

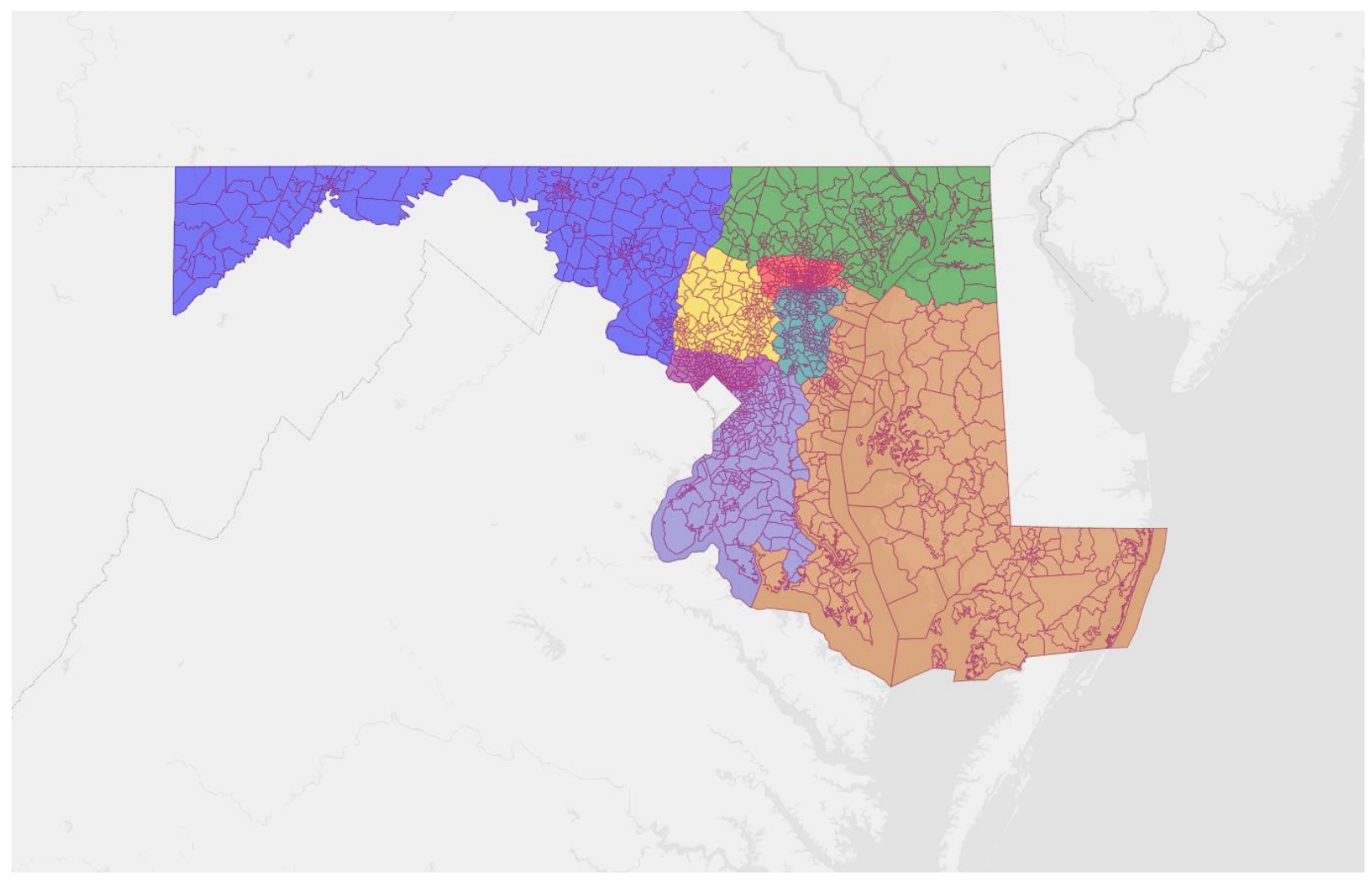




\section{MISSISSIPPI}

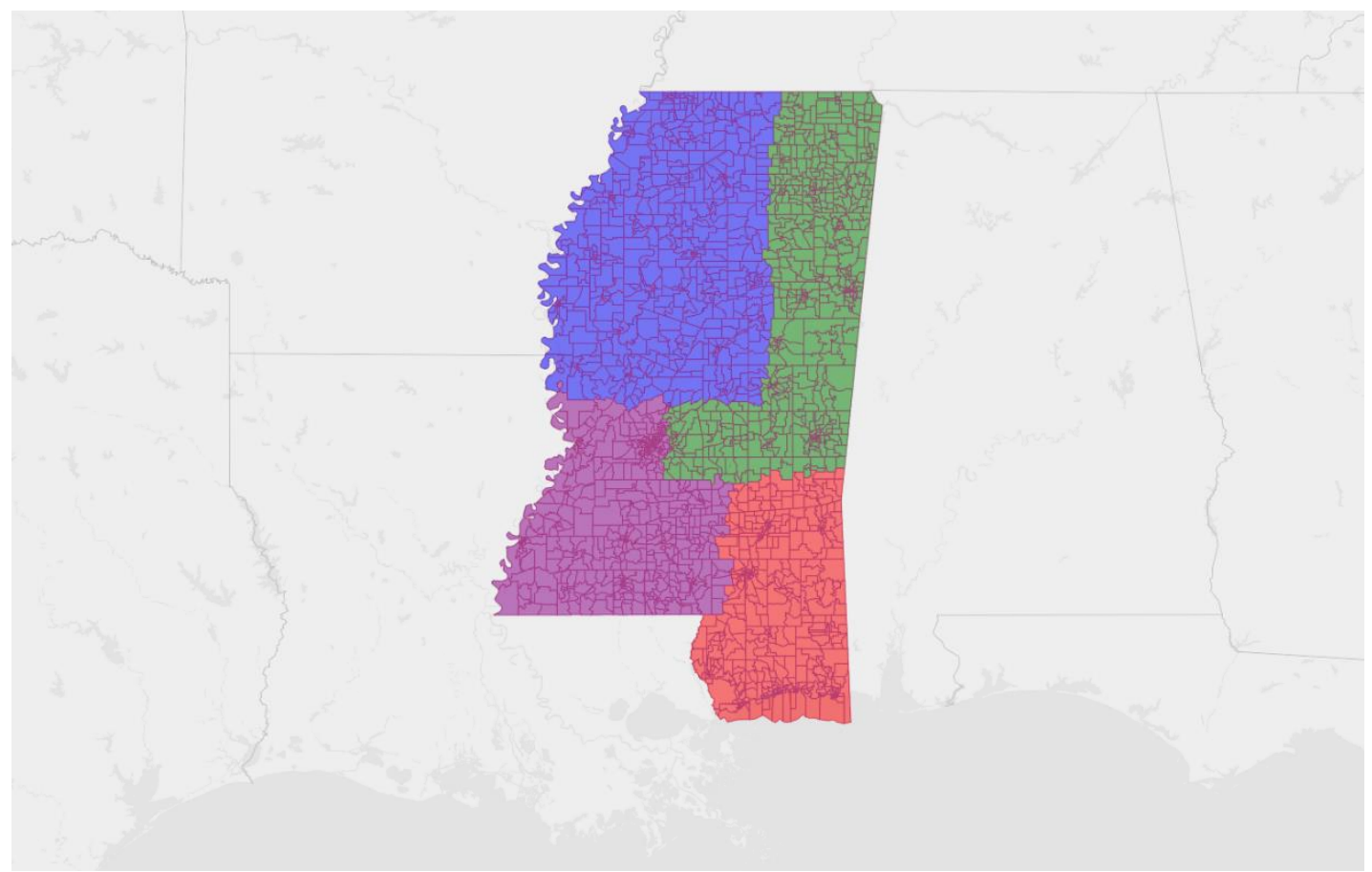

\section{OHIO}

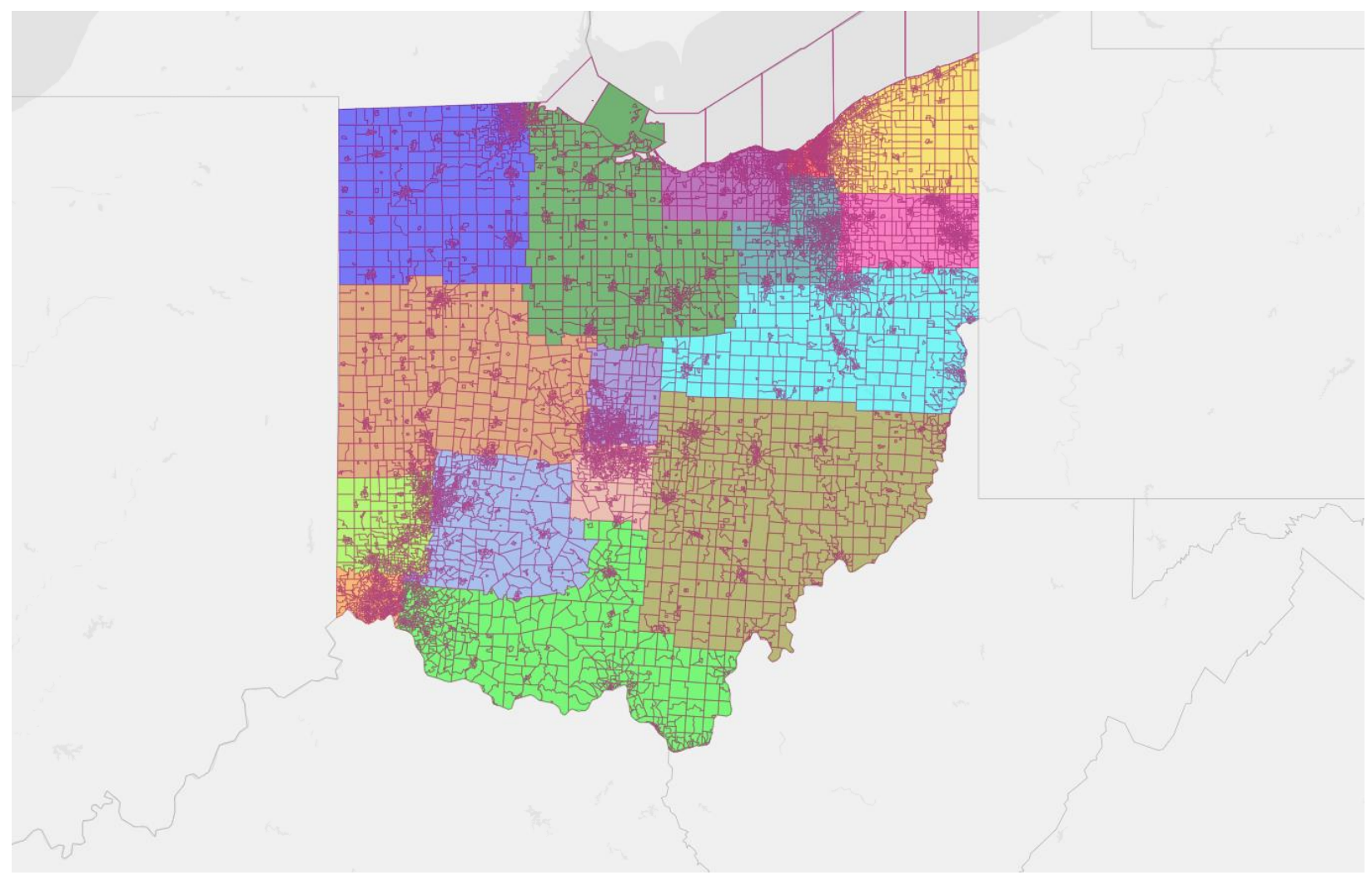




\section{TEXAS}

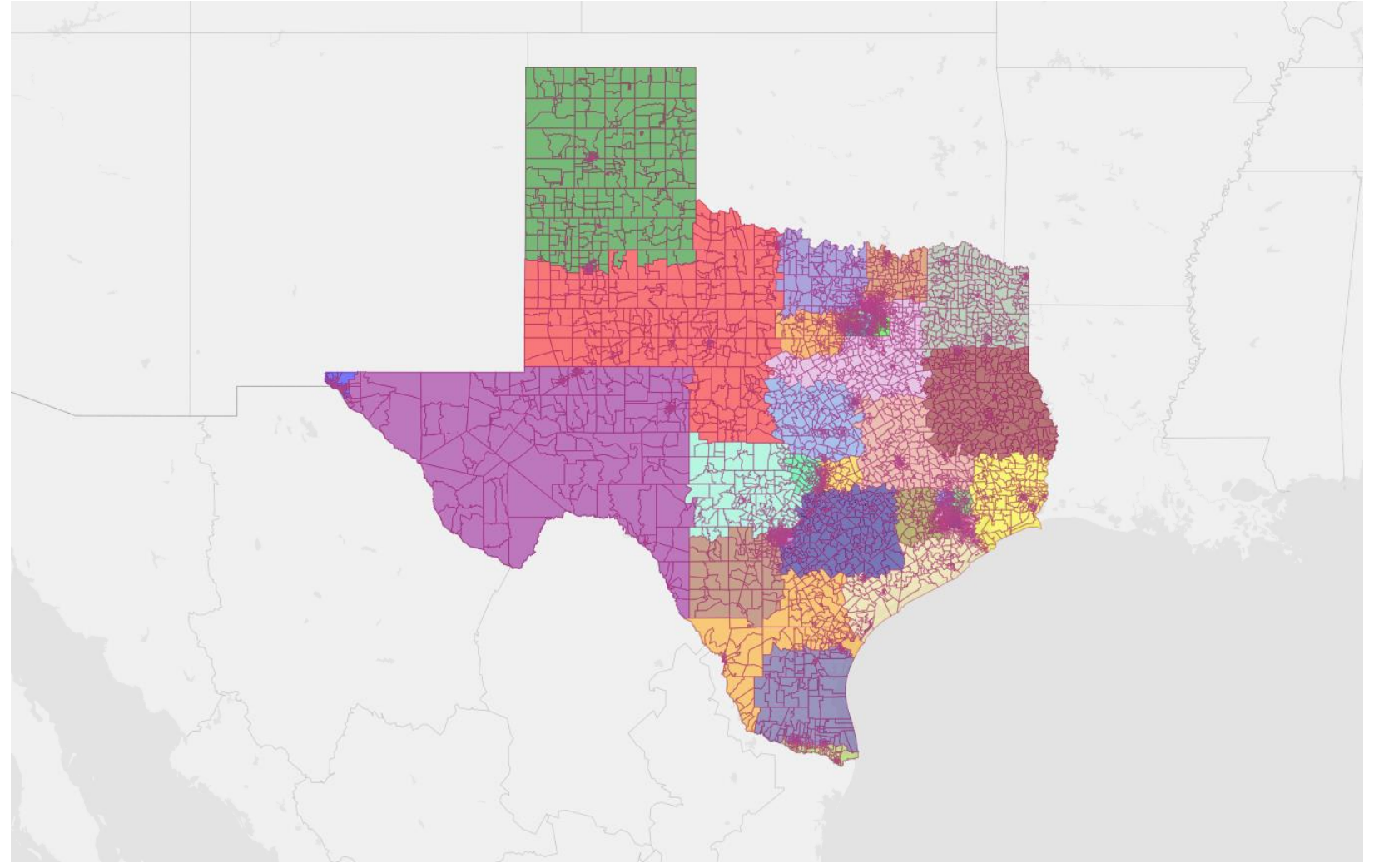

References

Altman, Micah and Michael McDonald. 2010. "The Promise and Perils of Computers in Redistricting.” Duke Journal of Constitutional Law \& Public Policy 5(1): 69-111.

Bradlee, Dave, Terry Crowley, Mike Mathiew and Alec Ramsay. 2020. "DRA 2020.” http://gardow.com/davebradlee/redistricting/default.html

Cook, Charles (ed.) n.d. The Cook Political Report. https://cookpolitical.com/pvi-map-and-district$\underline{\text { list }}$

"Evenwel v. Abbott." 2016. Leading Cases. Harvard Law Review 130(1).

(https://harvardlawreview.org/2016/11/evenwel-f-abbott/)

Gilbert, Craig. 2018. "New election data highlights the ongoing impact of 2011 GOP redistricting in Wisconsin.” Milwaukee Journal Sentinel. Dec. 6.

https://www.jsonline.com/story/news/blogs/wisconsin-voter/2018/12/06/wisconsin-gerrymanderingdata-shows-stark-impact-redistricting/2219092002/

Gill v. Whitford. 2017. No. 16-1161. Supreme Court Oral Arguments. https://www.supremecourt.gov/oral arguments/argument transcripts/2017/16-1161 bpm1.pdf

GISGeography. n.d. https://gisgeography.com/state-outlines-blank-maps-united-states/ 
Grofman, Bernard and Gary King. 2007. "The Future of Partisan Symmetry as a Judicial Test for Partisan Gerrymandering after LULAC v. Perry.” Election Law Journal 6(1): 2-35.

Hirsch, Sam. 2003. "The United States House of Unrepresentatives: What Went Wrong in the Latest Round of Congressional Redistricting.." Election Law Journal 2(2): 179-216.

Katz, Jonathan, Gary King and Elizabeth Rosenblatt. 2019. "Theoretical Foundations and Empirical Evaluations of Partisan Fairness in District-Based Democracies." American Political Science Review 114(1): 164-178.

Kaufman, Aaron, Gary King and Mayya Komisarchik. Forthcoming. "How to Measure Legislative District Compactness If You Only Know It When You See It." American Journal of Political Science. Copy at https://gking.harvard.edu/files/gking/files/compact.pdf

Levitt, Justin. 2018. “All About Redistricting.” http://redistricting.lls.edu/wherestate.php\#compactness.

Mellnik, Ted and Tim Meko. 2019. "North Carolina has a new congressional map for 2020." The Washington Post. Dec. 3.

Michael Li, Thomas Wolf and Annie Lo. 2019. "Where Redistricting Cases Are Still Pending." https://www.brennancenter.org/blog/state-redistricting-litigation.

Missouri Constitution. https://ballotpedia.org/Article III, Missouri Constitution.

National Conference of State Legislatures (NCSL). 2019. "Redistricting Criteria." Washington, D.C.: National Conference of State Legislatures. ncsl.org/research/redistricting/redistrictingcriteria.aspx

Ohio Bipartisan Redistricting Commission Amendment, Issue 1. 2015.

https://ballotpedia.org/Ohio Bipartisan Redistricting Commission Amendment, Issue 1 (2015)

Olson, Brian. n.d. "BDistricting." https://bdistricting.com/about.html\#for.

Rakich,, Nathaniel, 2018. "Everything is Partisan and Correlated and Boring," FiveThirtyEight. https://fivethirtyeight.com/features/everything-is-partisan-and-correlated-and-boring/

Rucho v. Common Cause 18-422, 588 U. S. ___ (2019).

https://www.supremecourt.gov/opinions/18pdf/18-422 9ol1.pdf

Wang, Samuel, Richard Ober and Benjamin Williams. Forthcoming. "State Constitutions and Partisan Gerrymandering (February 13, 2019)." University of Pennsylvania Journal of Constitutional Law. Available at SSRN: http:dx.doi.org/10.2139/ssrn.3335622.

Wikipedia, (e.g.) https://en.wikipedia.org/wiki/Alabama\%27s congressional districts 